This document is published in:

Journal of Monetary Economics (2003), 50 (6), 1257-1291. DOI: http://dx.doi.org/10.1016/S0304-3932(03)00078-3

C 2003 Elsevier B.V. 


\title{
Precautionary savings and wealth distribution under habit formation preferences ${ }^{\text {is }}$
}

\author{
Antonia Díaz ${ }^{\mathrm{a}}$, Josep Pijoan-Mas,*, José-Victor Ríos-Rull ${ }^{\mathrm{c}, \mathrm{de,f}}$ \\ ${ }^{a}$ Department of Economics, Universidad Carlos III, 28093 Getafe Madrid, Spain \\ ${ }^{\mathrm{b}}$ Centro de Estudios Monetarios y Financieros, (CEMFI), Casado del Alisal, 5, 28014 Madrid, Spain \\ ${ }^{\mathrm{c}}$ Department of Economics, University of Pennsylvania, Philadelphia PA 19104, USA \\ ${ }^{\mathrm{d}} C A E R P, U S A$ \\ ${ }^{\mathrm{e}} C E P R, U S A$ \\ ${ }^{\mathrm{f}} N B E R, U S A$
}

\begin{abstract}
We study the role of habit formation in shaping the amount of precautionary savings and the wealth distribution in heterogeneous agents model economies with idiosyncratic uncertainty. We adjust preferences to equate the Intertemporal Elasticity of Substitution in all model economies. We find that habit formation brings a hefty increase in precautionary savings and very mild reductions in the coefficient of variation and in the Gini index of wealth. These findings hold for both persistent and non-persistent habits, with the effects of the former being much larger.
\end{abstract}

JEL classification: D31; D91; C68

Keywords: Habit formation; Precautionary savings; Wealth distribution

\footnotetext{
${ }^{25}$ The previous version of this paper had the title "Habit Formation: Implications for the Wealth Distribution". We are grateful to the attendants to the V Workshop in Dynamic Macroeconomics, Vigo, July 2000, 2001 North American Summer Meeting of the Econometric Society, Washington, 2001 Annual Meeting of the Society for Economic Dynamics, Stockholm, XXV Simposio de Análisis Económico, Alicante, December 2001, and to seminar participants in University College of London, Universidad Carlos III de Madrid, and Universidad Autónoma de Barcelona for their very constructive comments. We thank Michele Boldrin for comments in the first stages of this research. Díaz thanks the Spanish Ministry of Education, DGI, project BEC2001-1653, for financial support. Pijoan-Mas thanks the Bank of Spain for financial support and the Economics Department of University of Pennsylvania for its hospitality. Ríos-Rull thanks the National Science Foundation for Grant SES-0079504 and the University of Pennsylvania Research Foundation for their support. Pijoan-Mas and Ríos-Rull thank the Centro de Altísimos Estudios Ríos Pérez for its hospitality.

*Corresponding author. Tel.: + 34-91-429-0551; fax: +34-91-429-1056.

E-mail address: pijoan@cemfi.es (J. Pijoan-Mas).
} 


\section{Introduction}

Models with a large number of ex-ante identical agents with standard preferences subject to uninsurable, idiosyncratic shocks to income are the main tool used to answer two questions that many economists see as important: (1) what is the size of precautionary savings (savings held for the sole purpose of smoothing consumption across different contingencies)?, and (2) what accounts for the very large differences in assets holdings among American households? The accepted answ er to the first question as posed, for example, by Aiyagari (1994) is that precautionary savings are small, no more than $3 \%$ of total savings. With respect to the second question, there is a debate about the extent to which a theory of wealth inequality can be based on standard and identical preferences and on uninsurable shocks to income. ${ }^{1}$

In this paper we study, in the context described in the previous paragraph, the role played by habit formation in determining the volume of precautionary savings and in shaping the distribution of wealth, and hence, the answers to those two important questions.

Habit formation has been recently used to improve the predictions of timeseparable models in different fields where savings behavior under uncertainty and the income-fluctuation problem are the chief ingredients. For instance, some authors have pursued this path and studied various formulations of habit formation to improve our understanding of the equity premium puzzle. ${ }^{2}$ Other authors have used this class of preferences to study the observed relationship betw een savings and grow th. Finally, Fuhrer (2000) show show the presence of habits in consumption can generate slow and hump-shaped reactions of consumption to monetary and other shocks. Despite all this w ork with habits, ${ }^{4}$ its implications for

\footnotetext{
${ }^{1}$ For example Krusell and Smith (1998) postulate shocks to preferences to account for wealth inequality w hile Carroll (2000) argues that we should use models where consumers consider the accumulation of wealth as an end in itself or models where wealth yields a large unobservable flow of services. Quadrini and Ri'os-Rull (1997) contains a review of the literature and its successes and failures in accounting for w ealth inequality with uninsurable shocks to income. On the other hand, recently Castan eda et al. (2001), argues that a suitably modified version of the basic model with identical and standard preferences and uninsurable shocks does account for the wealth inequality observed in the U.S. An important modification proposed by these authors is the use of a process for earnings with more volatility than those found in previous work.

${ }^{2}$ Abel (1990) and Constantinides (1990) show that adding habit formation to an otherwise standard exchange model economy, the equity premium puzzle as stated by Mehra and Prescott (1985) disappears. The same result is obtained by Heaton (1995), Boldrin et al. $(1997,2001)$ and Campbell and Cochrane (1999).

${ }^{3}$ The evidence show s that, across countries and across households, the grow th rate of income has a positive and significant effect on the savings rate (see Edw ards(1995), Carroll and Weil (1994), Deaton and Paxson (1994), for instance). To account for this observed pattern Carroll et al. (2000) modify the standard $A k$ model to display habit formation. They show that the model is successful to replicate the positive response of the savings rate to the grow th rate of income.

${ }^{4}$ In this work, as in ours, households do not value leisure. The role of time non-separabilities in leisure is dormant since its early appearance in quantitative theory in Kydland and Prescott (1982). Also we do not look at the feature opposite to habit formation, that is durability of consumption, even though in the context of our model preferences could display durability of consumption by simply setting one parameter to a negative value. The reason is that the definition of wealth that we use already includes a large fraction of the stock of consumer durables.
} 
the determination of precautionary savings and for shaping the wealth distribution have not been explored. This is precisely the target of this paper.

There are reasons to think that the habit formation hypothesis may have a significant role in shaping the wealth distribution and in determining the size of precautionary savings. Households with habits want, not only a smooth pattern of consumption, but also a smooth pattern of changes in consumption. This implies that households in habits economies dislike consumption fluctuations to a larger extent than their counterparts in a world of time-separable preferences. This should increase the amount of precautionary savings. How much it will is one of the quantitative questions we address. Any effect on wealth concentration relies on an asymmetric impact, over different types of agents, of the habit formation hypothesis on the disutility of consumption fluctuations. On the one hand, when bad times strike, households will deplete their assets faster to ensure a mild decrease in consumption. But on the other hand, anticipating this problem, they will have accumulated some extra assets. In equilibrium, which force will dominate for each type of agent? This is the key for the second quantitative question addressed in the paper.

There is a variety of attempts trying to quantify the size of precautionary savings. The econometric literature offers diverse answers that range from being very small Dynan (1993) to the quite large Carroll and Samwick (1998). ${ }^{5,6}$ Within the macroeconomic literature, there are some attempts to measure the importance of precautionary savings using models with a large number of ex-ante identical agents subject to uninsurable, idiosyncratic risk. Within a partial equilibrium context Hubbard et al. (1994) find that idiosyncratic uncertainty implies an increase in the aggregate capital-income ratio of 0.90 percent, w hile Carroll and Samw ick (1997) find that households facing higher uncertainty accumulate more w ealthalthough such response is much low er than the one predicted in Hubbard et al. (1994). ${ }^{7}$ Finally, Cagetti (2000) finds that for individuals under 50 years old almost all savings respond to precautionary motives and that at the age of retirement wealth is tw iceas high as in a world without diosyncratic uncertainty. How ever,in general equilibrium models the size of precautionary savings is substantially reduced, the reason being that, as aggregate savings increase, their return fall. Aiyagari (1994) in a infinite horizon economy finds that precautionary savings are small, no more than 3 percent of total savings. Huggett (1996) finds similar result in a life-cycle economy.

Thus, the accepted answer, at least within the context of general equilibrium models, seems to be that precautionary savings are small. As stated before, habit

\footnotetext{
${ }^{5}$ They estimate that between 39 and 46 percent of wealth of individuals under 50 years is attributable to the extra uncertainty that some consumers face compared to the lowest uncertainty group.

${ }^{6}$ See Browning and Lusardi (1996) for a survey of the empirical literature on precautionary savings.

${ }^{7}$ In particular, Carroll and Samwick (1997) show that to obtain a level of responsiveness of w ealth similar to Hubbard et al. (1994) estimates, the rate of time preference should be as high as 11 percent, as opposed to Hubbard et al. (1994) who use a rate of 3 percent.
} 
formation provides an extra reason for further expanding the precautionary motive in spite of the fall in the return on savings. ${ }^{8}$

To study the role of habits we compare a standard economy without habits (the benchmark economy) with various habits counterparts. We proceed by first looking at economies with the same parameterization except for the habits. The two economies do not have the same intertemporal elasticity of substitution (henceforth IES). Hence, households in the habits and in the benchmark economy not only differ in their attitude towards risk, but also in their willingness to intertemporally substitute consumption. To better understand the implications of habits, we compare the benchmark economy with the habits economies recalibrated to have the same IES. To further study the role of habits in shaping wealth inequality we want to isolate the effect of habits on risk aversion from the induced effects brought by the changes in the interest rate that go together with the associated changes in risk aversion. To this end, we compare the benchmark economy with the habits economies calibrated to have not only the same IES, but also the same aggregate savings. To analyze the effect of the persistence of habits on the level of precautionary savings and wealth inequality we study two habits economies: one in which habits respond very quickly to changes in consumption (non-persistent) and other in which the response of habits is very slow (persistent).

We find that the presence of habits generates a volume of precautionary savings whose size goes from two to three times the volume of precautionary savings generated by the standard model, depending on the habits persistence. With respect to inequality we find that habits do decrease wealth inequality as measured by the coefficient of variation and the Gini Index by about 10 and 18 percent also depending on habits persistence (for instance, the Gini Index is 0.404 in the benchmark model without habits and it goes down to 0.339 in one of the habits economies). The reason for this decrease in wealth inequality is the different effect that habits has on households depending on their level of wealth: wealth poor households increase their precautionary savings more than wealth rich ones do. There are two reasons for this: first, other things equal, wealth rich households have a smaller proportion of their income in form of risky labor earnings, and, second, wealth rich households have higher buffer stocks to smooth out consumption fluctuations (as a matter of fact, even without habit formation they are already very well self-insured, so there is no big need for extra cover in face of the higher disutility of consumption fluctuations).

These results, as we have stated, depend on the persistence of the habits process. When the habit stock is not persistent (as when instance habits depend only on the consumption of the previous period) the effect on households' behavior is much weaker than when the habit stock is persistent (as when it is given by the whole history of past consumption). The reason for this is that households care about fluctuations of consumption around their habit stock. Given a change in

\footnotetext{
${ }^{8}$ However, we should note that these findings are made in an economy with very little wealth disparity which implies that there are very few agents close to the assets positions that leave them vulnerable to adverse shocks.
} 
consumption, when the habit process is (not) persistent, it takes many (few) periods to catch up with the consumption level and therefore variations of consumption over the habit stock are big (small) as it is the utility loss.

These findings, although quantitatively smaller, also hold in model economies that generate Gini coefficients closer to those in the data. ${ }^{9}$ In this case precautionary savings are between 1.5 and 2.7 its size in the non-habits economy (where they are quite large) and the reduction in the inequality measures ranges between 3 and 8 percent. The larger changes correspond to economies with persistent habits. Thus, our assessment is that while the effect of habits in precautionary savings can be very big, the overall effect in wealth inequality is milder.

In this paper the vector of state variables includes both habits and assets, two variables directly controlled by the household. This feature complicates the numerical methods involved which leads us to use multidimensional splines to solve the problem of the household. We consider of independent value the procedures that we use to compute equilibria and we describe them in more than the usual detail.

Section 2 describes the model, while Section 3 describes the calibration process. Section 4, describes the findings, while Section 5 explores the robustness of the findings with respect to the process for earnings. Section 6 concludes. Appendix A describes how we solved the problem of the agent and how we computed equilibria, while Appendix B describes how the IES is calculated in different economies and Appendix $\mathrm{C}$ describes the values of two measures of risk aversion for habits economies.

\section{The model economy}

The economy is a growth economy with production populated by a measure one of households that live forever. We only look at steady states. Section 2.1 describes preferences with habits. Sections 2.2 and 2.3 describe the technology, including the production sector, the shock process that affect households and the market arrangements. In Section 2.4 we write down the households problem while Section 2.5 presents a formal definition of steady state equilibrium.

\subsection{Preferences}

Households derive utility from current and past consumption. Current consumption is denoted by $c$. Past consumption affects the level of a stock of habits that we denote with $h \in[0, \infty)$. We write the evolution of habits as $h^{\prime}=\psi(c, h)$, where we already use the recursive notation that is pervasive throughout the paper with primes denoting next period's values. We write the per period utility as $u(c, h)$, and total utility as $\sum_{t=0}^{\infty} \beta^{t} u\left(c_{t}, h_{t}\right)$. Notice that, since current consumption affects future per

\footnotetext{
${ }^{9} \mathrm{We}$ get this large wealth differences by calibrating the process for labor earnings as proposed by Castañeda et al. (2001).
} 
period utilities (by means of $h_{t}$ ), preferences over consumption are not timeseparable.

The term habits refers to preferences where an increase in $h$ lowers the utility derived from a given level of consumption: $\partial u(c, h) / \partial h<0$. When this is positive the term used is durability, and it has very different considerations.

\subsection{Technology}

Each period households receive a shock to their efficiency units of labor $e \in E=\left\{e_{1}, \ldots, e_{n_{e}}\right\}$. This shock is Markov with transition matrix, $\pi_{e, e^{\prime}}$.

Aggregate output, $Y$, is produced according to an aggregate neoclassical production function that takes as inputs capital, $K$, and efficient units of labor, $L$, $Y=F(K, L)$. The aggregate labor input comes from aggregating all agents' efficiency units of labor. Aggregate capital results from aggregation of all assets. Capital depreciates at rate $\delta \in[0,1]$.

\subsection{Market arrangements}

There are no state contingent markets for the household specific shock, $e$. Households hold assets $a \in A \equiv[\underline{a}, \infty)$ that pay interest at rate $r$. We assume that households are restricted by a lower bound on their assets holdings $\underline{a}$. This lower bound may arise endogenously as the quantity that ensures that the household is capable of repaying its debt in all states of the world or we can just set it exogenously as a borrowing constraint. ${ }^{10}$ The absence of state-contingent markets and the presence of borrowing constraints are the ingredients needed to depart from the representative agent framework which is silent about distributional issues in the cross-section. ${ }^{11}$

\subsection{The household's problem}

Since we only look at steady states, the individual household's state variables are its shock, its assets and its stock of habit, $\{e, a, h\}$. The problem that the household solves is

$$
\begin{aligned}
v(e, a, h) & =\max _{c \geqslant 0, a^{\prime} \geqslant \underline{a}} u(c, h)+\beta \sum_{e^{\prime}} \pi_{e, e^{\prime}} v\left(e^{\prime}, a^{\prime}, h^{\prime}\right) \\
\text { s.t. : } \quad a^{\prime} & =e w+(1+r) a-c, \\
h^{\prime} & =\psi(c, h),
\end{aligned}
$$

where $r$ and $w$ are the return on assets and the rental rate for efficiency units of labor.

\footnotetext{
${ }^{10}$ See Huggett (1993) and Aiyagari (1994) for details. Quadrini and Ríos-Rull (1997) contains a review on this topic.

${ }^{11}$ See Chatterjee (1994) or Alvarez and Dí az (2000).
} 
It is well known that under certain conditions problems of this type have a solution that we denote $a^{\prime}=g^{a}(e, a, h), c=g^{c}(e, a, h)$ with an upper bound on asset holdings, $\bar{a}$ and on the stock of habits $\bar{h}$, such that $\bar{a} \geqslant g^{a}(e, a, h) \geqslant \underline{a}$ and $\bar{h}>$ $\psi\left(g^{c}(e, a, h), h\right)>0$, for all $e \in E$, all $h \in\{h \mid 0 \leqslant h \leqslant \bar{h}\}$, and all $a \in\{a \mid \underline{a} \leqslant a \leqslant \bar{a}\}$. Sometimes we use the compact notation $s=\{e, a, h\}$ and $S=\{E \times[\underline{a}, \bar{a}] \times[0, \bar{h}]\}$. With respect to assets, the required conditions amount to have a low enough rate of return, $\beta<1 /(1+r)$. Again, see Aiyagari (1994), Huggett (1993), or Quadrini and Ríos-Rull (1997) for details. With respect to habits, it suffices to have a bounded $\psi$.

It is possible to construct a Markov process for the individual state variables, from the Markov process on the shocks and from the decision rules of the agents (see Huggett (1993) or Hopenhayn and Prescott (1992) for details). Let $\mathscr{B}$ be the $\sigma$-algebra generated in $S$ by, say, the open intervals. A probability measure $x$ over $\mathscr{B}$ exhaustively describes the economy by stating how many households are of each type. Note that the first moment of $x$ over $e$ yields the aggregate labor input while the first moment over $a$ yields aggregate capital.

Let $Q(s, B)$ denote the probability that a type $\{s\}$ has of becoming of a type in $B \subset \mathscr{B}$. Function $Q$ naturally describes how the economy moves over time by generating a probability measure for tomorrow $x^{\prime}$ given a probability measure $x$ today. The exact way in which this occurs is

$$
x^{\prime}(B)=\int_{S} Q(s, B) \mathrm{d} x .
$$

If the process for the earnings shock is nice in the sense that it has a unique stationary distribution, then so has the economy. ${ }^{12}$ Furthermore, this unique stationary distribution is the limit to which the economy converges under any initial distribution. ${ }^{13}$

\subsection{Equilibrium}

We have almost all the ingredients to define a steady state equilibrium. We only need to add the condition that marginal productivities yield factor prices as functions of $x$. Note that to obtain a steady state, we look for a measure of households $x$ such that given the prices implied by that measure, households actions reproduce next period the same measure $x$. Formally, a steady state equilibrium for this economy is a set of functions for the household problem $\left\{v, g^{a}, g^{c}\right\}$, and a measure of households, $x$, such that: (i), Factor inputs are obtained aggregating over households: $A=\int_{S} a \mathrm{~d} x$, and $L=\int_{S} e \mathrm{~d} x$; (ii), factor prices are factor marginal productivities, $r=F_{1}(K, L)-\delta$, and $w=F_{2}(K, L)$; (iii), given $x, K$, and $L$, the functions $\left\{v, g^{a}, g^{c}\right\}$ solve the households' decision problem described in Section 2.4; (iv), the goods

\footnotetext{
${ }^{12}$ For example if it satisfies the American-dream American-nightmare condition stated in Ríos-Rull (1998), then there is a unique stationary distribution of households over earning shocks, assets holdings and stock of habits.

${ }^{13}$ This does not mean that this will happen in equilibrium outside the steady state. The transition $Q$ has been constructed under the assumption that the households think that prices are constant.
} 
market clears: $\int_{S}\left[g^{c}(s)+g^{a}(s)\right] \mathrm{d} x=F(K, L)+(1-\delta) K$, and $(\mathrm{v})$, the measure of households is stationary: $x(B)=\int_{S} Q(s, B) \mathrm{d} x$, for all $B \subset \mathscr{B}$.

\section{Calibration}

This paper explores the role of habits in quantitatively shaping the size of precautionary savings and the $w$ ealth distribution. To do this, w e compare economies identical in every respect but the specification of preferences: while in a benchmark economy preferences display no habit formation, in the other economies preferences display habits. We start by choosing the benchmark model economy to be essentially a version of Aiyagari (1994) that has become the standard in the literature that measures the size of precautionary savings. We describe the calibration of the benchmark model economy in Section 3.1 and that of the model economies with habits in Section 3.2.

Once we have a benchmark model economy without habits we have to calibrate the economies with habits. There is not a unique way to do this, since habits have been modelled in at least two ways. On the one side, there is a survival consumption branch. Past consumption piles up into a habit stock that determines a minimal consumption for today, below which utility is not defined. ${ }^{14}$ On the other side, there is a multiplicative habit branch. Past consumption piles up into a habit stock that enters utility dividing today's consumption, capturing the notion that, under habit formation, it is not consumption level but relative consumption what matters. ${ }^{15}$ Therefore, the two different approaches differ in two dimensions. First, the survival consumption household cares about the absolute difference between consumption and habit stock whereas the multiplicative habit consumer cares about the relative difference. And second, for the survival consumption household, consuming below the minimal level given by the habit stock is not defined (death) whereas it is well defined for the multiplicative habit consumer.

Regarding the first difference, the survival consumption representation has been preferred by authors working with the representative agent hypothesis in the field of asset pricing. As Campbell and Cochrane (1999) claim, one needs this formulation to get the equity premium negatively correlated with the cycle. ${ }^{16}$ However, Krusell and Smith (1997) show that once we allow for heterogeneous agents an economy with no habits can deliver a negative correlation between the equity premium and the cycle. Furthermore, Pijoan-Mas (2003) shows that this last result is preserved when adding a multiplicative habit in the heterogeneous agents economy.

Regarding the second difference, it is difficult to reconcile the survival habit approach with individual data. Even in the most conservative earnings process, any

\footnotetext{
${ }^{14}$ Pioneered by Ryder and Heal (1973) and follow ed for instance by Constantinides (1990), Heaton (1995), Boldrin et al. (1997) or Dynan (2000).

${ }^{15}$ Used for instance by Abel (1990), Carroll et al. (2000) or Fuhrer (2000).

${ }^{16}$ Campbell and Cochrane (1999) put it this w ay: "As consumption declines tow ard the habit in a business cycle through, the curvature of the utility function rises". In particular, the Arrow-Pratt measure of risk aversion rises as consumption falls tow ard the habit.
} 
household can see its labor earnings halved between two consecutive periods. If one wants to replicate the U.S. data Gini coefficient for earnings, being unlucky may mean dividing earnings by a factor of 9 (see Section 5) in one period or even by 45 in two periods (in an extreme bad luck case). The survival habit utility function can hardly accommodate this variation in earnings if households do not accumulate huge precautionary savings. In contrast, variations in earnings in aggregate data are not so sharp and fit well in the survival consumption utility function.

We choose to work with the multiplicative habit utility function. The reason is twofold. First, the motives that brought the survival consumption representation into the picture are absent here. Namely, to have a representative agent economy display certain properties of data that an heterogeneous agents economy already does with the multiplicative habit. And second, since we calibrate and simulate our model economies to represent individual behavior, the computational problem associated to solving the model when consumption falls below habit in the survival consumption case becomes very big. However, in Section 4.5 we also provide some simulations for the survival consumption utility function to show that the qualitative results are the same.

We choose to study two types of habits that differ in their persistence. Essentially persistent habits imply that current consumption enters negatively the per period utility function of all future periods, albeit in a decreasing manner. Non-persistent habits are those where the influence of current consumption ends next period since the per period utility function only depends on yesterday's and on today's consumption.

We have to choose not only the type of habits, but we also have to be very specific with respect to what is the habits counterpart to our benchmark model economy. We propose a sequence of economies in increasing order of appropriateness. First, we think of the habits economy as an economy like the benchmark with the addition of the term in habits but keeping constant all other parameters.

Habit formation breaks the link between risk aversion and the IES. Thus, economies that keep their parameterization identical to that of the benchmark model economy except for the specification of habits differ in the IES. For this reason we also compare the benchmark economy with another model economy with habits but adjusted so that it has the same IES. This is achieved by changing one parameter of preferences.

We explore the role of habits in shaping the distribution of wealth. Part of our interest is in the size of precautionary savings, but another important part of our concerns is inequality. We want to separate the effects of habits on both characteristics and for this reason we also investigate an economy that has not only the same IES as the benchmark model economy, but also the same of total savings.

\subsection{The benchmark model economy (no habits)}

In the benchmark model economy, preferences are of the CRRA form, $\sum_{t} \beta^{t}\left(c_{t}^{1-\sigma}-1\right) /(1-\sigma)$ and we set a period to be one year. Parameter $\beta$ is set at 0.96 , which places the equilibrium interest rate around $4 \%$. We set the IES, $1 / \sigma$ to be 
equal to 0.5 , a value that is around those most preferred by economists. This is our only departure from Aiyagari (1994) in the benchmark model economy since for all other choices w e mimic his values. ${ }^{17}$ Production occurs through a standard neoclassical production function $F\left(K_{t}, L_{t}\right)=K_{t}^{\theta} L_{t}^{1-\theta}$. Capital share is equal to 0.36 and the depreciation rate of capital $\delta$ is set equal to 0.08 . Note that these are all standard values.

With respect to the process for earnings, Aiyagari (1994) sets an AR(1) in the logarithm of labor income. The process is fully described by two parameters: its persistence and its volatility. He chooses both values following estimates of Kydland (1984) that used PSID data and of Abow d and Card (1987) and Abowd and Card (1989) that used both PSID and NLS data. Then, he approximates the process by using a seven state Markov chain following the procedures described in Tauchen (1986). We follow the same directions although we reduce the Markov chain to three states. ${ }^{18}$ We take our benchmark to be an autocorrelation of 0.6 and a coefficient of variation of $0.2 .{ }^{19}$ We later provide results for an economy that has a lot more earnings dispersion, an economy capable of generating wealth dispersion more in accordance with the data. ${ }^{20}$ The specific parameter values that we choose are summarized in Table 1.

\subsection{Calibration of the economies with habits}

As we have already stated, we use the specification of preferences used by Carroll et al. (2000) and Fuhrer (2000) based on that of Abel (1990) where the stock of habits $h$ enters multiplying the level of consumption. The per period utility function is

$$
u(c, h)=\frac{\left(c h^{-\gamma}\right)^{1-\sigma}-1}{1-\sigma}=\frac{\left[c^{1-\gamma}(c / h)^{\gamma}\right]^{1-\sigma}-1}{1-\sigma}, \quad 1>\gamma>0 .
$$

The second way of writing the specification highlights the fact that consumers care about a composite good which is a weighted average of the absolute value of consumption (being rich or being poor) and the relative level of consumption with respect to the past (being better or worse than usual). For $\gamma=0$ we are in the

\footnotetext{
${ }^{17}$ Aiyagari (1994) uses values of 1, 0.33 and, 0.2. Ghez and Becker (1975) and MaCurdy (1981), both using a life cycle model and explicitly accounting for leisure postulate a lowvalue. Mehra and Prescott (1985) and Prescott (1986) discuss other estimates in the literature and conclude that a reasonable number is not too far from 1 (notice that the models they use have quarters as periods). Cooley and Prescott (1995) point out that this parameter is among the most difficult to pin down and settle for a value of 1 . Hurd (1989) has a point estimate below one.

${ }^{18}$ As we describe below, habits introduce an additional choice state variable which dramatically increases the computational costs of the project. By choosing three states we reduce computer time drastically in a margin that has never proved to be important.

${ }^{19}$ Aiyagari (1994) provides results for autocorrelations of 0.0, 0.3, 0.6 and 0.9 and for coefficient of variations of 0.2 and 0.4 .

${ }^{20}$ Aiyagari (1994) fails to account for the amount of wealth inequality in the U.S. The highest value of the coefficient of variation of assets in any of his model economies is 1.13 compared to 6.09 in the data. As Castañeda et al. (2001) points out, this is in part due to the process of earnings that he chooses. According to Díaz-Gimenez et al. (1997) the coefficient of variation for U.S. earnings from the 1992 Survey of Consumer Finances is as big as 4.19 whereas the largest value Aiyagari uses is 0.4.
} 
Table 1

Parameter values of the benchmark model economy

\begin{tabular}{llll}
\hline $\begin{array}{l}\text { General parameters } \\
\beta\end{array}$ & $\sigma$ & & \\
0.96 & 2 & 0.36 & $\delta$ \\
Earnings process & & & \\
$e \in e_{1}, e_{2}, e_{3}=$ & 0.78, & 1.00, & 1.27 \\
& {$\left[\begin{array}{lll}0.66 & 0.27 & 0.07 \\
0.28 & 0.44 & 0.28 \\
0.07 & 0.27 & 0.66\end{array}\right]$} \\
$\pi_{e, e^{\prime}}=$ & & & \\
& & & \\
Stationary distribution & 0.337 & 0.326 & 0.337 \\
$\pi^{\star}=$ & &
\end{tabular}

no-habits case: only absolute consumption matters. For $\gamma=1$ we are in the opposite case: only relative consumption matters. Notice, hence, that the same reason that makes households willing to smooth consumption levels is going to make them willing to smooth the ratio of consumption over the habit stock (so they are better off with several small changes than with a single big change).

The evolution of the stock of habits is given by the function

$$
h^{\prime}=\psi(c, h)=(1-\lambda) h+\lambda c, \quad \lambda \in(0,1] .
$$

Thus, the level of habit is a weighted average of the stream of past consumption. The parameter $(1-\lambda)$ measures the persistence of the habit stock. The higher the value of $\lambda$ the lower the duration of the influence of current consumption in future per period utilities. ${ }^{21}$ As $\lambda$ decreases the effect of $c$ in future utilities increases and the ability of current consumption to modify the habit stock is reduced. ${ }^{22}$

Calibrating the basic habits model economy requires choosing values for the parameters $\lambda$ and $\gamma$. Notice that the benchmark model economy has a representation under this parameterization: the value of $\gamma$ is zero (which makes irrelevant the value of $\lambda$ ).

There are several studies that try to estimate the parameters of habit formation in consumption. Some use individual level short panels, whereas some others use aggregate time series. Some try to find out which parameterizations are consistent

\footnotetext{
${ }^{21}$ Notice that for $\lambda=1$ we are in the particular case that today's habit stock is only yesterday's consumption or, in other words, today's consumption only affects tomorrow's utility.

${ }^{22}$ Notice also that setting $\lambda=0$ is not equal to the limit case of $\lambda \rightarrow 0$. One can rewrite the law of motion for habits as $\tilde{h}^{\prime}=(1-\lambda) \tilde{h}+c$ where $\tilde{h} \equiv h / \lambda$ because $\lambda$ is just a constant that does not affect the maximization. Under this representation we see that the role of $\lambda$ is solely to control the persistence of the process and does not affect the strength of consumption in the habit stock. However, we cannot do this normalization when $\lambda=0$ because it would imply dividing the utility function by zero, which does affect the maximization. Therefore, in this particular case $\lambda$ is doing two things, namely, setting the persistence of habits equal to one and saying that consumption does not affect the habit stock.
} 
with certain asset pricing regularities whereas some others try to estimate consumption demand functions or first order conditions. ${ }^{23}$ The heterogeneity of data sets and techniques rises to a very wide range of possible values for our $\gamma$ and $\lambda$. Ideally, we would be looking for estimations consistent with our model in functional forms and length of period. Unfortunately, this is hard to find.

The closest model to ours is the one by Fuhrer (2000) who uses quarterly data on aggregate consumption data in non-durable goods and services (from NIPA) to estimate a log-linearized consumption function where habits enter multiplicatively in the utility function as in our model. He estimates $\gamma=0.8$ and $\lambda=0.9985$. An estimation of $\sigma=6.11$ is consistent with the IES $=0.5$ we use throughout the paper. ${ }^{24}$

Constantinides (1990) and Boldrin et al. (1997) try to find w hich pairs of parameters are consistent $\mathrm{w}$ ith the observed risk premium and $\mathrm{w}$ ith both the observed risk premium and risk free rate respectively. However, they use the survival consumption formulation to introduce habits in the utility function. Boldrin et al. (1997) find the best fit with the equivalent to our notation of $\gamma=0.58$ and $\lambda=0.70 .^{25}$ Constantinides finds several pairs that fit the risk premium, with weight of habit $\gamma$ ranging from 0.09 to 0.49 and corresponding persistence parameter $\lambda$ ranging from 0.10 to $0.37 .^{26}$ Although these papers solve the equity premium puzzle as stated by Mehra and Prescott (1985) they still have some counterfactual implications as the excessive unconditional variance of the risk free rate. Heaton (1995) performs a similar experiment with monthly aggregate time series in non-durable consumption and services by NIPA getting $\gamma=0.71$ and $\lambda=0.58$. How ever, he also sets a more ambitious framew ork allow ing for habit formation and consumption durability to interact (and not to offset each other as in Ferson and Constantinides (1991)) and targeting not only first moments of asset returns but also second moments. With this larger moments set he finds $\gamma=0.00$ and $\lambda=1.0$ if a pure habit model is used (which is evidence against habits) but $\gamma=0.67$ and $\lambda=0.18$ if interaction with durability is allow ed for. In this last case we see a very high persistence (in monthly data) not found in other studies. ${ }^{27}$

\footnotetext{
${ }^{23}$ There are some others that just test for the presence of habit formation without estimating any closed form. A good example of these is Meghir and Weber (1996).

${ }^{24}$ Fuhrer (2000) also allows for a fraction of agents not to behave rationally but just to eat all their current income. He estimates this fraction to be $25 \%$ of the total population.

${ }^{25}$ This is an abuse of notation because their formulation is different from ours. We can somehow "translate" parameters from one to the other seeing the survival consumption representation as $u\left(c_{t}, h_{t}\right)=$ $\left(c_{t}-h_{t}\right)^{1-\sigma} /(1-\sigma)$ and $h_{t+1}=(1-\lambda) h_{t}+\gamma c_{t}$.

${ }^{26}$ Constantinides $(1990)$ represents $u\left(c_{t}, h_{t}\right)=\left(c_{t}-h_{t}\right)^{1-\sigma} /(1-\sigma)$. The discrete time version of the law of motion for the stock of habits he uses is $h_{t}=(1 /(1+a))^{t} h_{0}+b \sum_{i=1}^{t}(1 /(1+a))^{i-1} c_{t-i}$. Thus, we translate $\lambda=1-1 /(1+a)$ and $\gamma=b$.

${ }^{27} \mathrm{Tw}$ o other important papers in the asset pricing literature with habit formation are Campbell and Cochrane (1999) and Boldrin et al. (2001). However, they do not seem to us such a useful reference for calibrating our habit process. The former paper sets up an external process for the habit stock, that is to say, the habit stock does not depend on individual consumption but on aggregate consumption instead, something that is also known as keeping up with the Jones. In the steady state of our economies aggregate variables are constant and therefore an external habit stock would also be a constant. The latter paper is an effort to put together asset pricing and business cycles in a model with many ingredients beyond habit formation.
} 
Table 2

Basic parameters of the habits economies

\begin{tabular}{lll}
\hline & $\gamma$ & $\lambda$ \\
\hline Low persistence economy & 0.75 & 1.00 \\
High persistence economy & 0.75 & 0.25 \\
Benchmark model economy & 0.00 & - \\
\hline
\end{tabular}

Dynan (2000) also uses the survival consumption formulation with individual level data on food consumption from PSID. Because of data restrictions she imposes $\lambda=1.0$ (i.e., only yesterday consumption matters) to find that $\gamma$ cannot be said to be different from zero. ${ }^{28,29}$

We find Fuhrer estimation as the closest one to our formulation. Since he uses quarterly data and we are calibrating for a model period of one-year length we see his $\gamma=0.8$ as an upper bound and end up choosing $\gamma=0.75$. As for the persistence parameter, we work with a pair of values at each side of the possible range: $\lambda=1.0$ and $\lambda=0.25$. The former is consistent $w$ ith Fuhrer estimation $w$ hereas the latter, acknow ledging the diversity of empirical results, will show us what happens at the other side of the persistence range. ${ }^{30,31}$ Our choices are described in Table 2.

\subsection{The value of the IES}

With CRRA preferences and no habit formation, preferences over different periods in time and over different contingencies are the same. Adding time nonseparable preferences breaks this symmetry. As shown by Constantinides (1990) and Boldrin et al. (1997), habit formation breaks the link betw een the IES and the level of risk aversion. In order to disentangle the effect of habit formation in each dimension we look at model economies with habit formation exhibiting the same IES as our benchmark so that the results show theeffect of habits on preferences over uncertain levels of consumption, not over intertemporally distributed consumption. In Appendix B w eshow that, along a balanced growth path, IES $=1 /(\gamma+(1-\gamma) \sigma){ }^{32}$ This tells us tw o things. First, if individuals are not

\footnotetext{
${ }^{28}$ She has the same problem as Meghir and Weber (1996). Time dimension in individual level data is very short and does not allow for estimations of persistent habits.

${ }^{29}$ She uses the survival consumption formulation with individual data. This also helps finding $\gamma$ not different from zero since it is very difficult to accommodate the large individual variability of consumption with the endogenous survival consumption level unless $\gamma$ is very small.

${ }^{30} \mathrm{We}$ have obviously tried different values of $\gamma$. In none of our experiments $\gamma$ has changed the qualitative results. $\gamma$ behaves just as an amplifier of the habit phenomenon.

${ }^{31} \mathrm{We}$ find interesting to explore a low lambda in spite of Fuhrer's findings because of the following. Meghir and Weber (1996) and Dynan (2000) reject the hypothesis of habit formation using individual level data. How ever, the lack of long time series forces them to equalize habit stock to previous period consumption. If habits are very persistent, as Heaton (1995) suggests, it might well be the case that their rejection of the habit hypothesis is driven by the fact that, under very persistent habits, yesterday's consumption ability to modify the habit stock is small.

${ }^{32}$ Carroll et al. (2000) already show this result in a continuous time $A k$ grow th model.
} 
financially constrained, preferences towards consumption in different moments of time do not depend on the persistence of the habit stock, $(1-\lambda)$, but only on the magnitude of habits in the utility function, $\gamma$. Second, with habit formation preferences towards consumption in different moments of time exhibit less curvature than without habit formation (in other words, households desire less consumption smoothing). ${ }^{33}$ The reason for this being, as posed by Carroll et al. (2000), that "the gain or loss in utility associated with a given increase or decrease in consumption over a long horizon will be diminished by the associated movement in the habit stock". Therefore, when we want to keep IES as in the benchmark economy given $\gamma$, we will adjust $\sigma$.

\section{Results}

In this section we report the findings from the various model economies. The results have been computed by solving the household's problem with a twodimensional spline tensor product (that we ensure generates a concave function). We construct a sample of 5000 households. ${ }^{34}$ Then, using the decision rule, the law of motion for the exogenous state and a random number generator, we simulate the decisions of these households to find a new distribution of households. We iterate until the main statistics of the samples converge. Then, we compare the statistics generated for all the economies studied by using in all of them the same realizations of the random numbers. ${ }^{35}$

In Section 4.1 we review the Aiyagari (1994)'s model economy, which we will refer to as the benchmark economy hereafter. We compare his findings to those of the representative agent deterministic version of his economy. Notice that the main statistics of the representative agent deterministic version of our model with habits are the same as those of the model without habits. Section 4.2 describes the properties of economies with habits, without any further adjustments. Sections 4.3 and 4.4 show the results for economies with habits where we recalibrate our model economy so that, respectively, IES and total savings match those of the economy without habits. Section 4.5 looks at survival habits.

\subsection{The benchmark model economy}

The main characteristics of the benchmark model economy, that we refer to sometimes as economy $B$, are described in Table 3 .

The first column shows the values of the key statistics of the deterministic representative agent counterpart of the benchmark economy. ${ }^{36}$ We denote this

\footnotetext{
${ }^{33}$ For $\sigma>1$ and $0<\gamma<1$.

${ }^{34} \mathrm{We}$ have also tried larger samples. We see that sample sizes beyond our choice do not change aggregate results. However, for histograms and for reporting the shares of certain groups we use a larger sample size of 50000 .

${ }^{35}$ For further details, see Ríos-Rull (1998).

${ }^{36}$ The deterministic model has been calibrated with the same parameters as those used in the benchmark economy and setting the labor endowment equal to the unconditional mean of the earning process.
} 
Table 3

Main statistics of the benchmark economy and its deterministic counterpart

\begin{tabular}{lllr}
\hline & $\begin{array}{l}D \\
\text { Deterministic } \\
\text { economy }\end{array}$ & $\begin{array}{l}B \\
\text { Benchmark } \\
\text { economy }\end{array}$ & $\begin{array}{l}\text { Change } \\
\frac{B-D}{D} * 100\end{array}$ \\
\hline Aggregate assets & 2.959 & 3.015 & $1.9 \%$ \\
Output & 1.000 & 1.007 & $0.7 \%$ \\
Capital output ratio & 2.959 & 2.994 & $1.2 \%$ \\
Interest rate & $4.17 \%$ & $4.02 \%$ & $-3.5 \%$ \\
Coeff. of variation of wealth & 0.0 & 0.748 & - \\
Gini index of wealth & 0.0 & 0.404 & - \\
\hline
\end{tabular}

economy as $D$. As we see the interest rate is $4.17 \%$ and the capital output ratio is 2.959. For comparison purposes, we have normalized output to one in this deterministic economy. The second column includes the statistics of the benchmark model economy. We also report two measures of wealth dispersion, the coefficient of variation and the Gini Index. The last column reports the proportional variation in the main statistics of the benchmark model economy with respect to the deterministic economy. Note that both economies have different interest rates. This means that agents are responding to different prices. ${ }^{37} \mathrm{We}$ want to highlight two main things from this table. First, precautionary savings, that we define as the excess in total wealth that a given economy has over its deterministic counterpart, are small, less than $2 \%$, confirming Aiyagari's findings. Second, under this parameterization, assets holdings are very evenly distributed. The Gini coefficient, for example, is 0.40 while is 0.78 in the U.S. data.

\subsection{The unadjusted habits' economies}

As stated, we compare two habits economies with the benchmark model economy. Except for the existence of habits, the two habits economies have the same parameterization as the benchmark model economy. They differ from each other in the persistence of the habits. The second column of Table 4 reports the main statistics of what we refer as the non-persistent habit economy, or economy $N$, while the fourth column refers to the persistent habit economy, or economy $P$. The third and fifth columns have the rates of change between the habits economies and the benchmark model economies. ${ }^{38}$

\footnotetext{
${ }^{37}$ In fact if in the benchmark model economy the interest rate were set exogenously at the level of the deterministic economy, total assets will be unbounded. See Huggett (1993), Aiyagari (1994), Ríos-Rull (1998).

${ }^{38}$ As in the previous Subsection, we are looking at the general equilibrium version of the economies where the interest rates adjust to ensure that aggregate asset holdings equate aggregate capital. This means that interest rates are different than in economy $B$. If we keep fixed the interest rate (without letting it clear markets) we see what happens in absence of this price effect. Economy $N$ has total assets of 2.87 and economy $P$ of 4.11 , which clearly shows much larger changes than their general equilibrium counterparts.
} 
Table 4

Main statistics of the benchmark and the unadjusted habits economies

\begin{tabular}{|c|c|c|c|c|c|}
\hline & $\begin{array}{l}B \\
\text { Benchmark } \\
\text { economy }\end{array}$ & $\begin{array}{l}N \\
\text { Non-pers. } \\
\text { habits } \\
\lambda=1\end{array}$ & $\begin{array}{l}\text { Change } \\
\frac{N-B}{B}\end{array}$ & $\begin{array}{l}P \\
\text { Pers. } \\
\text { habits } \\
\lambda=0.25\end{array}$ & $\begin{array}{l}\text { Change } \\
\frac{P-B}{B}\end{array}$ \\
\hline Aggregate assets & 3.015 & 3.012 & $-0.1 \%$ & 3.035 & $0.7 \%$ \\
\hline Output & 1.007 & 1.006 & $-0.0 \%$ & 1.009 & $0.2 \%$ \\
\hline Capital output ratio & 2.994 & 2.993 & $-0.0 \%$ & 3.007 & $0.4 \%$ \\
\hline Interest rate & $4.02 \%$ & $4.03 \%$ & $0.2 \%$ & $3.97 \%$ & $-1.3 \%$ \\
\hline Precautionary savings & $1.9 \%$ & $1.8 \%$ & $-4.6 \%$ & $2.6 \%$ & $34.4 \%$ \\
\hline Coeff. of var. wealth & 0.748 & 0.721 & $-2.7 \%$ & 0.669 & $-10.6 \%$ \\
\hline Gini index wealth & 0.404 & 0.393 & $-2.7 \%$ & 0.367 & $-9.2 \%$ \\
\hline
\end{tabular}

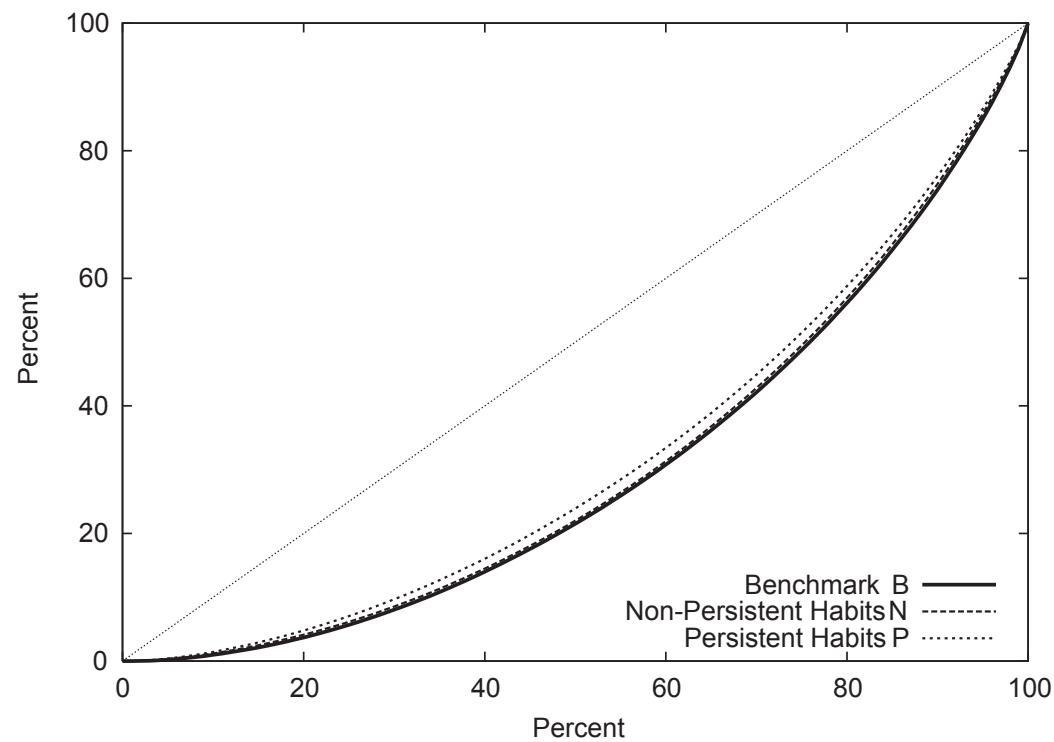

Fig. 1. Lorenz curve for assets: unadjusted economies, $\sigma=2, \beta=0.96$.

Regarding total assets, we see that both economies are quite similar to the nonhabits case. Aggregate savings are nearly unchanged, moving in opposite directions. Whereas in the non-persistent case they fall by just a $0.09 \%$, they increase by $0.67 \%$ in the persistent case. Movements in output and capital-output ratio follow. Even in the persistent economy, precautionary savings stay quite low, at $2.56 \%$. However, wealth dispersion changes more. With non-persistent habits, our measures of dispersion fall by about 3 percent but they fall about 10 percent with persistent habits.

Fig. 1 shows the Lorenz curves for assets of the three model economies. We see how similar are the benchmark and the non-persistent unadjusted habit model 


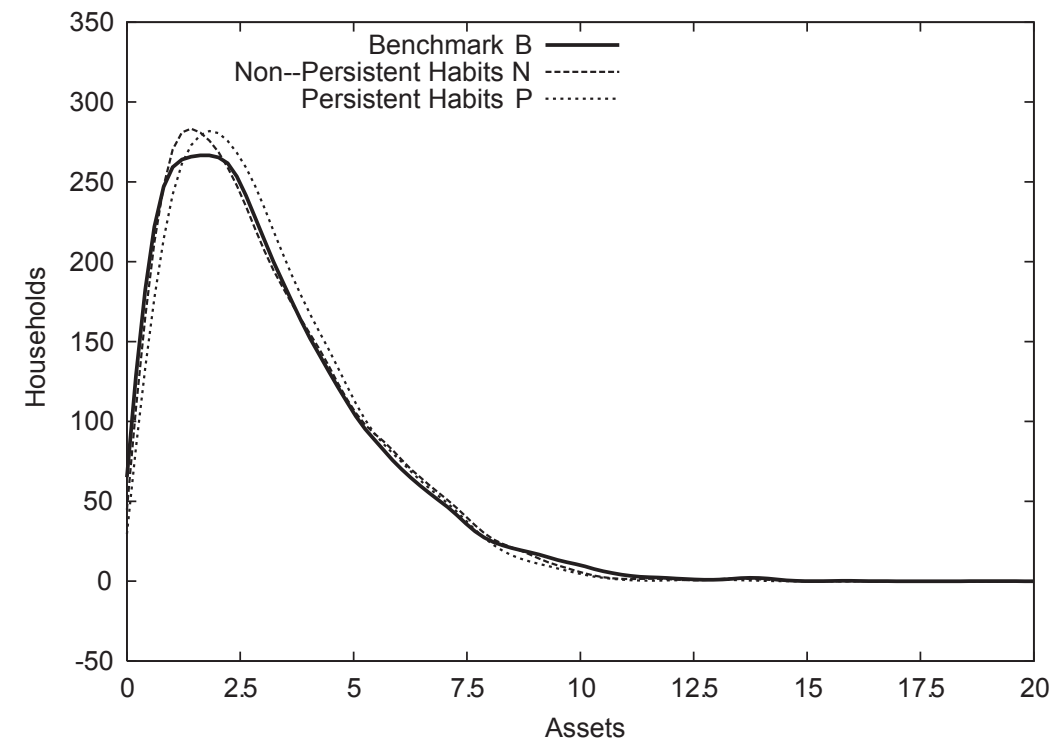

Fig. 2. Histogram for assets: unadjusted economies $\sigma=2, \beta=0.96$. General equilibrium.

economies while in the persistent unadjusted model economy the distribution is a little bit more even. We report the histograms of asset holdings in Fig. 2. The histogram shows quite similar pictures for all economies.

Overall, we see that for economies that differ only in the specification of habits from the benchmark model economy, the implied differences for precautionary savings are not very big. They fall slightly for the non-persistent economy and they increase for the persistent economy. This is a pattern we find throughout all experiments: precautionary savings are always larger for economies where habits are persistent than for economies where habits are non-persistent. Inequality indicators fall in both economies, more in the persistent case.

However, the differences we have seen between the benchmark economy and the habits economies cannot be solely attributed to the effect of habits. In particular, the benchmark model economy has an intertemporal IES $=0.5$ while that of the unadjusted economies with habits have a value of IES $=0.8$. This means that households in the unadjusted habits economies have a smaller desire to smooth consumption intertemporally. In the next subsection we report the properties of economies with habits, both persistent and non-persistent where the parameter $\sigma$ has been adjusted to generate a IES $=0.5$, the value of the benchmark model economy.

\subsection{Adjusting habits to match the IES}

Habits break the link between the individual's willingness to choose a contingent consumption plan, measured by the Coefficient of Relative Risk Aversion and the individual's willingness to intertemporally substitute consumption, measured by the 
Table 5

Main statistics of the benchmark and the adjusted habits economies IES $=0.5$

\begin{tabular}{lllllr}
\hline & $\begin{array}{l}B \\
\text { Benchmark } \\
\text { economy }\end{array}$ & $\begin{array}{l}M \\
\text { Non-pers. } \\
\text { habits } \\
\lambda=1\end{array}$ & $\begin{array}{l}\text { Change } \\
\text { M-B }\end{array}$ & $\begin{array}{l}\text { Pers. } \\
\text { habits } \\
\lambda=0.25\end{array}$ & $\begin{array}{l}Q-B \\
B\end{array}$ \\
\hline Aggregate assets & 3.015 & 3.066 & $1.7 \%$ & 3.126 & $3.7 \%$ \\
Output & 1.007 & 1.013 & $0.6 \%$ & 1.020 & $1.3 \%$ \\
Capital output ratio & 2.994 & 3.027 & $1.1 \%$ & 3.065 & $2.4 \%$ \\
Interest rate & $4.02 \%$ & $3.89 \%$ & $-3.2 \%$ & $3.75 \%$ & $-6.9 \%$ \\
Precautionary savings & $1.9 \%$ & $3.6 \%$ & $92.8 \%$ & $5.7 \%$ & $200.9 \%$ \\
Coeff. of var. wealth & 0.748 & 0.676 & $-9.6 \%$ & 0.611 & $-18.3 \%$ \\
Gini index wealth & 0.404 & 0.371 & $-8.2 \%$ & 0.339 & $-16.1 \%$ \\
\hline
\end{tabular}

IES. Each measure is the inverse of the other in the representative agent version of the benchmark economy, the economy without habits. This is no longer true in an economy with habits. Thus, to investigate the effect of habits on the level of precautionary savings we need to isolate the effect of habits on the level of risk aversion from the effect on the IES. In this subsection we recalibrate our habits economies so that the IES of the habits economies is the same as in the benchmark economy. ${ }^{39}$

Recall that in economies with habits IES $=1 /(\gamma+(1-\gamma) \sigma)$, where $\gamma$ is calibrated at 0.75 and IES targeted to 0.5 . This implies that $\sigma$ has to be increased to 5 . Notice that this means that households in the unadjusted habits economies of the previous section have substantially less desire for smoothing consumption over time than they will in the economy where we adjust $\sigma$. We have then two new model economies, an economy with non-persistent habits adjusted so that its IES $=0.5$, that we denote economy $M$, and an economy with persistent habits also adjusted to have its IES = 0.5 , that we denote economy $Q$.

The results are reported in Table 5. Notice that precautionary savings increase substantially in both economies with respect to the deterministic case. Now, they are $3.6 \%$ of total wealth in the deterministic case in the non-persistent habits economies and more than $5.6 \%$ in the persistent habits economies. So precautionary savings are between two and three times larger than in the benchmark model economy depending on the persistence. So habits indeed increase precautionary savings over the benchmark model economy, although perhaps their effect on aggregate capital is small.

With respect to wealth dispersion, we see an overall reduction of the inequality indicators, which is more evident in the economy with persistent habits where the reduction in inequality is more dramatic. Fig. 4 reports the histograms of asset holdings of the benchmark model economies and of the habits economies with IES $=0.5$. Here we start seeing a much clearer picture than in the economies with a

\footnotetext{
${ }^{39} \mathrm{We}$ are referring to the IES of the deterministic representative agent version of each model throughout the paper.
} 
larger IES. Inequality clearly goes down, especially for persistent habits. The Lorenz curves of the habits economies (see Figs. 3-4) are much closer to the diagonal than those in the benchmark model economy and the histograms seem to be much tighter.

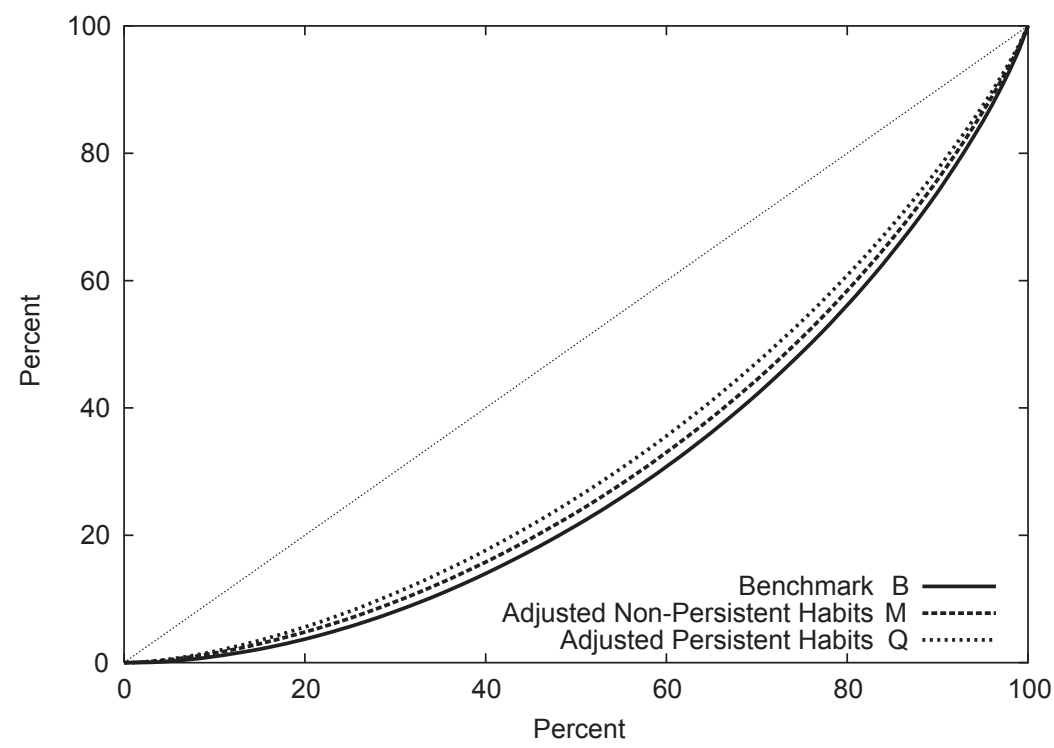

Fig. 3. Lorenz curve for assets: economies adjusted to the IES.

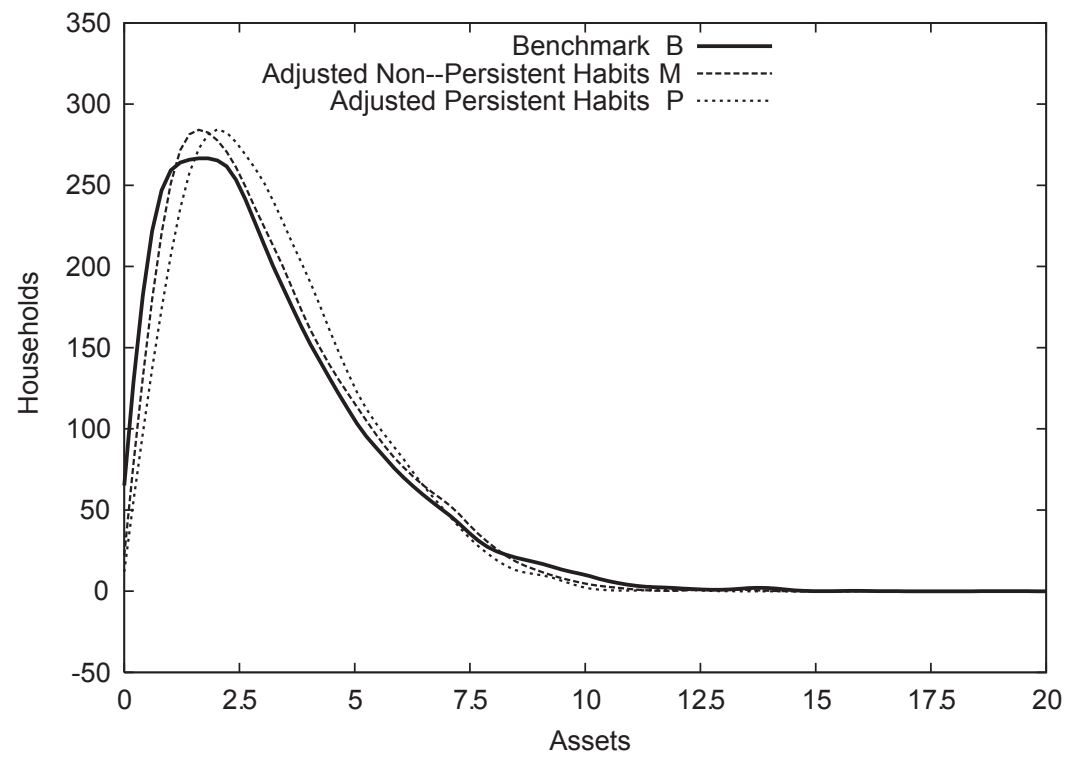

Fig. 4. Histogram for assets: economies adjusted to the IES. 
It is also more evident that a big part of the distributional differences are due to poor people: households in economies with habits, not wanting to face fluctuations on consumption, make sure they do not hold too low asset levels. In any case, the reduction of inequality as measured by the statistics that we have chosen is always less than 20 percent.

\subsection{Economies with the same savings as the benchmark model economy}

To finish we want to isolate the effects of habits on inequality from those on precautionary savings. To this end we perform a second adjustment on the habit economies. We adjust the parameter $\beta$ so that aggregate capital and hence the equilibrium interest rate is equal to that of the benchmark model economy.

We label $M^{\prime}$ and $Q^{\prime}$ the non-persistent and persistent economies respectively. Results are in Table 6 . As we can see the statistics for inequality are essentially identical to those for the economies of the previous subsection with the same $\beta$ as the benchmark model economy. Fig. 5 shows the Lorenz curves for assets of the benchmark model economy and of the habits economies adjusted to have the same IES and the same precautionary savings as the benchmark economy, while Fig. 6 reports their histograms of asset holdings. Both the Lorenz curve and the histogram resemble the ones already seen in the previous section, but with the value added for the histogram that the means of the distribution for the three economies are set to be equal. This allows us to see where the differences in wealth dispersion lie. We basically see that, as already stated, the habit economies have much fewer people in low levels of assets and more people about the mean, with hardly no differences in the high values. Again, this effect is stronger for persistent habits.

\subsection{An economy with survival habits}

We next explore the behavior of an economy with survival habits. The temporary utility function with survival habits can be written as $u\left(c_{t}, h_{t}\right)=\left(\left(c_{t}-\gamma h_{t}\right)^{1-\sigma}-1\right)$ / $(1-\sigma)$ while its law of motion for the habit stock is given by Eq. (6). We set parameters as in economies $N$ and $P$ except for parameter $\gamma$. We solve the economies

Table 6

Main statistics of the benchmark and the habits economies adjusted to have IES $=0.5$ and identical precautionary savings

\begin{tabular}{lllllr}
\hline & $\begin{array}{l}B \\
\text { Benchmark } \\
\text { economy }\end{array}$ & $\begin{array}{l}M^{\prime} \\
\text { Non-pers. } \\
\text { habits } \\
\lambda=1\end{array}$ & Change & $\begin{array}{l}Q^{\prime} \\
\text { Pers. } \\
\text { habits } \\
\lambda=0.25\end{array}$ & $\frac{Q-B}{B}$ \\
\hline$\beta$ & 0.960 & 0.959 & $-0.1 \%$ & 0.957 & $-0.3 \%$ \\
Coeff. of var. wealth & 0.748 & 0.678 & $-9.4 \%$ & 0.616 & $-17.6 \%$ \\
Gini index wealth & 0.404 & 0.372 & $-7.9 \%$ & 0.341 & $-15.6 \%$ \\
\hline
\end{tabular}




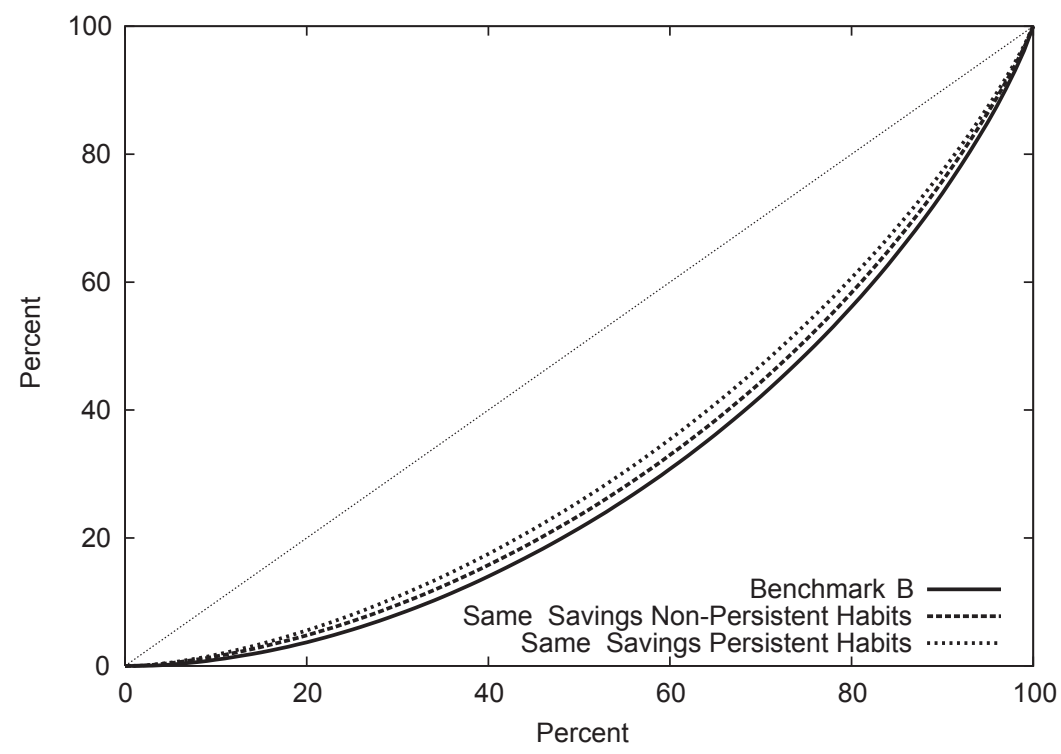

Fig. 5. Lorenz curve for assets: economies adjusted to savings, and IES.

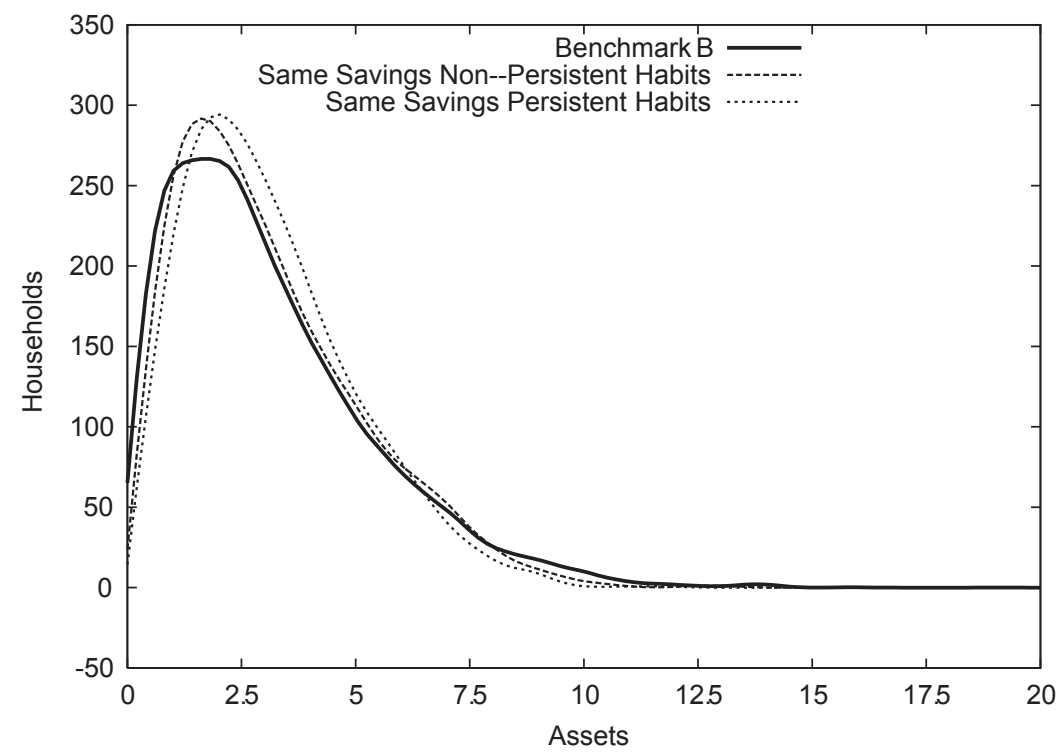

Fig. 6. Histogram for assets: economies adjusted to savings and IES.

for $\gamma=0.1$, a very low value. The reason is that habits affect very differently the different groups of agents. While it barely affects those agents with high consumption and high habits, it affects a lot agents with low habits and low 
Table 7

Main statistics of the benchmark and the survival habits economy $\gamma=0.10$

\begin{tabular}{llll}
\hline & $\begin{array}{l}\text { Benchmark } \\
\text { economy }\end{array}$ & $\begin{array}{l}\text { Non-pers. } \\
\text { habits } \\
\lambda=1\end{array}$ & $\begin{array}{l}\text { Pers. } \\
\text { habits } \\
\lambda=0.25\end{array}$ \\
\hline Aggregate assets & 3.015 & 3.015 & 3.017 \\
Output & 1.007 & 1.007 & 1.007 \\
Capital output ratio & 2.994 & 2.995 & 2.996 \\
Interest rate & $4.02 \%$ & $4.02 \%$ & 4.016 \\
Precautionary savings & $1.90 \%$ & $1.91 \%$ & $1.97 \%$ \\
Coeff. of var. wealth & 0.748 & 0.745 & 0.739 \\
Gini index wealth & 0.404 & 0.402 & 0.399 \\
\hline
\end{tabular}

consumption. This, which is not a problem in representative agent economies where there is very little variation in consumption, produces a very unstable computational problem. The problem is computationally particularly acute. We have to solve for many combinations of habits and wealth. Unfortunately many of those combinations prove lethal for the consumer (too much habit and to little wealth) producing negative values for $c-\gamma h$. It is difficult to rule out ex ante those combinations that consumers would try very hard to avoid. Addressing this issue properly will require some innovative computational procedures that dynamically determine which subset of pairs of assets and habits is relevant.

Table 7 shows the value of the main statistics for the model economy that we have been exploring. As we can see they are very similar to those of the benchmark model economy, indicating that the role of habits in these economies is very small. Precautionary savings are $1.9 \%$ and $2.0 \%$ respectively whereas Gini indices are 0.402 and 0.399 . Notice therefore the small increase in precautionary savings (even for the non-persistent case there is a tiny increase hidden by the rounding) and the fall in the inequality measures. Lemma 2 establishes that in these economies with survival habits the IES is given by $1 / \sigma$.

\subsection{Final comments}

We have seen two things: first, in habits economies precautionary savings are substantially higher and the level of wealth inequality is a little lower than in their non-habits counterparts and, second, these effects are stronger in economies with persistent habits. We comment each result in detail.

Households in habits economies are more displeased with fluctuations in consumption than their counterparts in economies without habits. Households with habits want not only a stable pattern of consumption but also a stable pattern of variations in consumption. Consequently, households in habits economies hold more assets. We see this in both the size of precautionary savings and in the shape of the lower tail of the distribution. Regarding the size of precautionary savings, we have seen that once adjusting $\sigma$ to keep IES unchanged, total precautionary savings doubles or triples depending on persistence, admittedly from quite a low value 
$(1.9 \%)$. Regarding the shape of the lower tail, we observe that it is asset-poor households who increase more their asset holdings. ${ }^{40}$ The reason for this is twofold. On the one hand, the share of uncertain labor earnings in their total income is higher for asset-poor households than for asset-rich households. On the other hand, assetpoor households are not well self-insured, which means that income fluctuations get easily translated into consumption fluctuations. On the contrary, asset-rich households have a stock of assets large enough to buffer fluctuations. So it is for the former households that an increase on the loss of utility due to consumption fluctuations is more likely to change savings behavior. This asymmetric impact of habits on asset-poor and asset-rich households accounts for the reduction in inequality.

Both effects on precautionary savings and on inequality are stronger for persistent habits. In Appendix $\mathrm{C}$ we show that along a balanced growth path, a measure of risk aversion in consumption (proposed by Boldrin et al. (1997)) is greater the higher the persistence in habits. (It also shows that risk aversion is higher than in economies without habits). This is because with persistent habits, a fall in consumption today has a small impact in lowering the habit stock for tomorrow. In contrast, the opposite is true when habits are non-persistent: a fall in consumption today is easily translated in a fall in the habit stock for tomorrow. Since not only the consumption level but also consumption relative to the habit stock matters, the fall in consumption is worse in utility terms if the habit stock stays stuck at its previous level than if it falls together with consumption. In a sense, non-persistent habits act as a safety net: being poor is not so bad because one gets easily used to it.

As we have stated, the overall effect on aggregate capital is not big. This is because the largest changes in savings behavior are done by asset-poor people, whose share of total assets is very small.

We turn next to explore whether these findings are specific to our parameterization or also hold for a larger set of model economies.

\section{Economies with high earnings variability}

One of the problems that Aiyagari's economy has in trying to match the U.S. wealth distribution is that the earnings distribution itself, an exogenous element, is already lacking dispersion. In his benchmark economy, he sets the coefficient of variation for the earnings distribution to be equal to 0.2 , which in our experiments gives a Gini index of 0.11 . The values of the Coefficient of variation and the Gini index for the U.S. economy are respectively 4.19 and $0.63 .{ }^{41}$ One interesting robustness analysis is, hence, to see how the conclusions change if we allow for an

\footnotetext{
${ }^{40}$ Quantitatively, the bottom $5 \%$ of the assets distribution have an average stock of assets of $0.13(0.2 \%$ share) in the benchmark economy whereas they have $0.27(0.4 \%)$ and $0.31(0.5 \%)$ in the economies labelled $M^{\prime}$ and $Q^{\prime}$. On the other side, for the top 5\% the average assets are $9.00(15.0 \%)$ for the benchmark and $8.11(13.5 \%)$ and $7.56(12.6 \%)$ for the economies $M^{\prime}$ and $Q^{\prime}$.

${ }^{41}$ See Díaz-Gimenez et al. (1997).
} 
Table 8

Earnings process of the high earnings variability economies

\begin{tabular}{lccr}
\hline$e \in e_{1}, e_{2}, e_{3}=$ & 1.00, & 5.29, & 46.55 \\
$\pi_{e, e^{\prime}}=$ & {$\left[\begin{array}{lll}0.992 & 0.008 & 0.000 \\
0.009 & 0.980 & 0.011 \\
0.000 & 0.083 & 0.917\end{array}\right]$} \\
$\pi^{\star}=$ & 0.481 & 0.456 & 0.063 \\
\hline
\end{tabular}

income process generating much more earnings inequality to a level similar to the U.S. data. Castañeda et al. (2001) calibrate the earnings process (among other features of their model economy) so that a suitably modified version of Aiyagari's model accounts for the Lorenz curve of wealth observed in the U.S. We construct a 3 point Markov process that has some of the properties of the 4 point Markov process of Castañeda et al. $(2001)^{42}$ that we report in Table 8. To get a high Gini coefficient w ith just three points in the Markov chain, one needs to make each state very different, in the process that we construct the endowment of the lucky households is almost 50 times the endowment of the unlucky ones. This process for earnings has a Gini index of $0.60 .^{43}$

We run the same experiments that we run for the low earnings volatility process with this new earnings process, following the same calibration procedures. The only difference lies in the parameter $\beta$ because we want the benchmark economy to have the same aggregate capital and interest rate as the benchmark economy with Aiyagari's earnings process. To do so, $\beta$ must be lowered from 0.96 to 0.887 . Higher variability calls for more precautionary savings.

What we find is that qualitative results remain unchanged. In the first panel of Table 9 we can see the no habits economy $B^{*}$ against what we called economies $M^{*}$ and $Q^{*}$ : those with non-persistent and persistent habits respectively with $\sigma$ adjusted to have the same IES as in the no-habits economy. In the no-habits economy precautionary savings are $134.3 \%$, a huge number compared to the $1.9 \%$ with Aiyagari's earnings process. This is the consequence of having such a big variability in earnings. Remember that in Aiyagari's earnings process the endowment in good time is less than $50 \%$ higher than the endowment in bad times, whereas in the high earnings variability process, the endowment in good times is about 50 times larger than in bad times. As before, the habits economies exhibit higher precautionary savings, being the increase larger for the economy $Q^{*}$ with persistent habits. In the non-persistent habits economy, precautionary savings are $50 \%$ larger while in the persistent habits economy, they are more than $150 \%$ larger. This time the increase is

\footnotetext{
${ }^{42}$ There are many ways of implementing this reduction. Our choice should be seen as merely illustrative for the study of the properties that habit formation has on Economies with high Earnings variability.

${ }^{43}$ The process estimated by Castañeda et al. (2001) includes retires and it w asdesigned for a model where households choose work effort. The process here is just intended to be in the ball park of that one. For instance, notice that even though the Gini Index is close to that in the data, its coefficient of variation is smaller than one-half that in the data.
} 
Table 9

Main statistics of the high earnings variability economies

\begin{tabular}{|c|c|c|c|c|c|}
\hline & $B^{*}$ & $M^{*}$ & & $Q^{*}$ & \\
\hline & No habits & $\begin{array}{l}\text { Non-pers. } \\
\text { habits } \\
\lambda=1\end{array}$ & $\begin{array}{l}\text { Change } \\
\frac{N-B}{B}\end{array}$ & $\begin{array}{l}\text { Pers. } \\
\text { habits } \\
\lambda=0.25\end{array}$ & $\begin{array}{l}\text { Change } \\
\frac{P-B}{B}\end{array}$ \\
\hline Aggregate assets & 3.015 & 3.848 & $27.7 \%$ & 5.948 & $97.3 \%$ \\
\hline Output & 1.007 & 1.099 & $9.2 \%$ & 1.285 & $27.7 \%$ \\
\hline Capital output ratio & 2.994 & 3.501 & $16.9 \%$ & 4.626 & $54.5 \%$ \\
\hline Interest rate & $4.02 \%$ & $2.28 \%$ & $-43.2 \%$ & $-0.22 \%$ & $-105.4 \%$ \\
\hline Precautionary savings & $134.3 \%$ & $199.1 \%$ & $48.2 \%$ & $362.3 \%$ & $169.8 \%$ \\
\hline Coeff. of var. wealth & 2.491 & 2.405 & $-3.4 \%$ & 2.274 & $-8.7 \%$ \\
\hline Gini index wealth & 0.857 & 0.831 & $-3.0 \%$ & 0.805 & $-6.1 \%$ \\
\hline
\end{tabular}

Habits economies adjusted to have IES $=0.5$ and identical precautionary savings.

\begin{tabular}{lrrrrr}
\hline & \multicolumn{1}{c}{$B^{*}$} & \multicolumn{1}{l}{$M^{*^{\prime}}$} & \multicolumn{2}{l}{$Q^{*^{\prime}}$} \\
\hline Precautionary savings & $134.3 \%$ & $201.6 \%$ & $50.2 \%$ & $455.3 \%$ & $239.1 \%$ \\
$\beta$ & 0.887 & 0.859 & $-3.1 \%$ & 0.781 & $-11.9 \%$ \\
Coeff. of var. wealth & 2.491 & 2.459 & $-1.3 \%$ & 2.486 & $-0.2 \%$ \\
Gini index wealth & 0.857 & 0.838 & $-2.2 \%$ & 0.830 & $-3.2 \%$ \\
\hline
\end{tabular}

over an already very large number, ${ }^{44}$ making the role of habits very important in shaping this variable.

The model economies display a much higher coefficient of variation and Gini indices than the economies with Aiyagari's earnings process. Moreover, the values of the Gini index are even larger than the 0.78 of U.S. data. ${ }^{45}$ This very high concentration of wealth can be seen both by means of the Lorenz curves plotted in Fig. 7, that are much closer to the bottom right corner than the earlier ones, and by means of the shares of wealth held by selected groups of households reported in Table 10 where we can see that the share of wealth of the bottom $40 \%$ is zero and that of the top $10 \%$ is about $77 \%$.

But what we really care about is the contribution of habits to shape inequality. We see that all our measures of inequality fall somewhat in the habits economies versus the no-habits economy, again more sharply for the economy with persistent habits. The main change in all economies occurs by having an increase in the share of the third and fourth quintiles at the expense of the fifth, especially of the households in

\footnotetext{
${ }^{44}$ Recall that these economies are parameterized so that the no-habits economy, $B^{*}$, has the same wealth as the benchmark model economy, $B$, and for this the discount rates have been reduced quite dramatically.

${ }^{45}$ As shown in Castañeda et al. (2001) this type of process accounts for wealth inequality in an economy with a lot more detail built in. The actual number of the version that we use in this paper is not so important. Here, we are not after accounting for wealth inequality, but we are trying to measure the role of habit formation in changing our answers about wealth inequality and precautionary savings.
} 

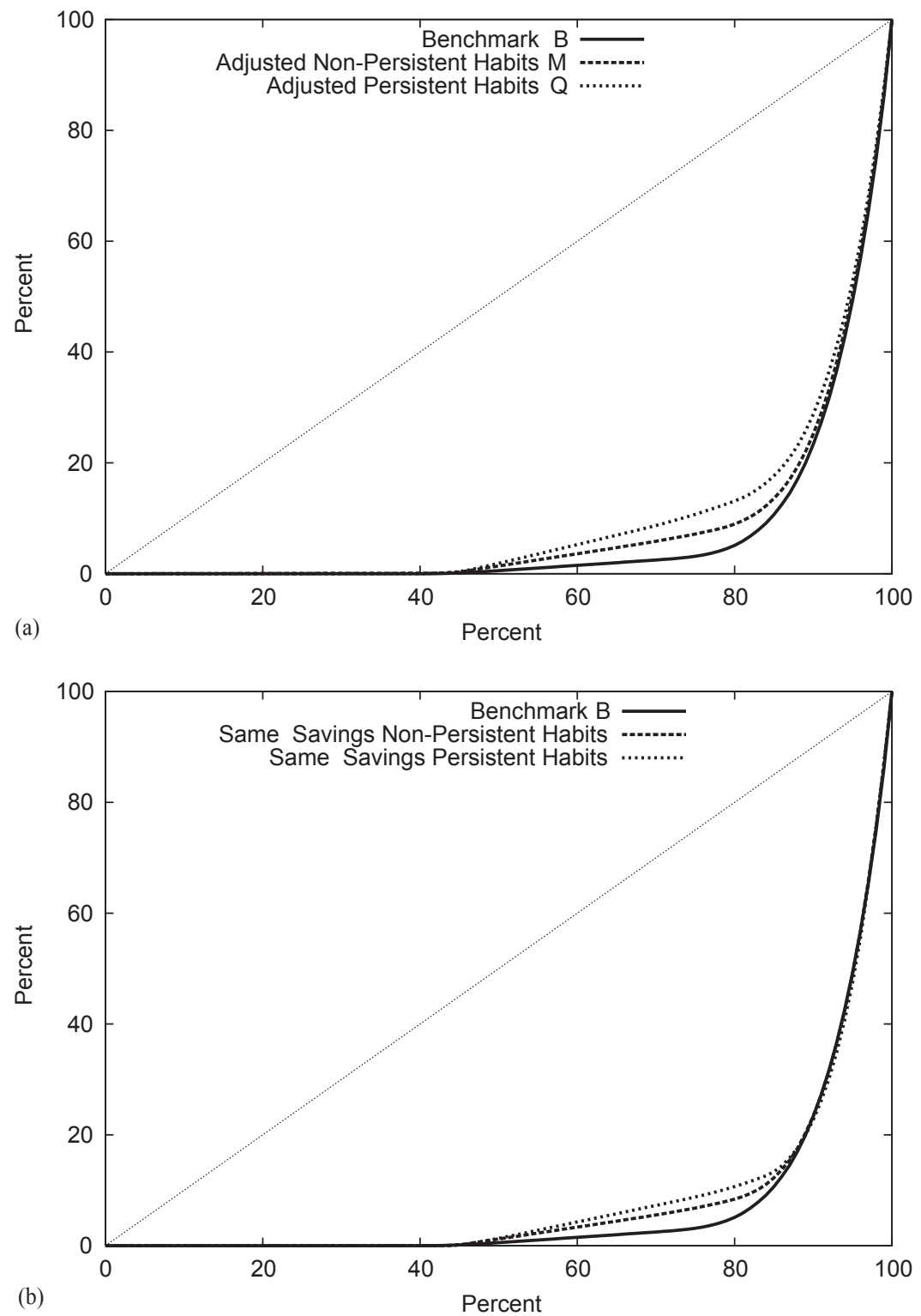

Fig. 7. Lorenz curve for assets: high earnings variability economies.

the $80-95$ percentiles. The fall of inequality in economies $w$ ith habits adjusted to have the same precautionary savings is almost zero. How ever, the distribution of w ealth has changed as it can be seen in Table 10, even if the total contribution of these changes to the coefficient of variation and the Gini Index is minimal. 
Table 10

The distributions of wealth in the high earnings variability economies

\begin{tabular}{|c|c|c|c|c|c|c|c|c|}
\hline \multirow[b]{2}{*}{ Economy } & \multicolumn{5}{|c|}{ Quintiles } & \multicolumn{3}{|c|}{ Top groups $(\%)$} \\
\hline & 1 st & $2 \mathrm{nd}$ & $3 \mathrm{rd}$ & 4 th & 5 th & Top $10 \%$ & Top 5\% & Top $1 \%$ \\
\hline$B^{*}$ (no habits) & 0.00 & 0.00 & 1.51 & 3.60 & 94.89 & 76.62 & 50.62 & 13.65 \\
\hline$M^{*}$ (IES-adj. non-pers) & 0.04 & 0.04 & 3.52 & 5.35 & 91.04 & 74.75 & 49.47 & 12.91 \\
\hline$Q^{*}$ (IES-adj. pers) & 0.01 & 0.02 & 5.23 & 7.85 & 86.89 & 71.21 & 47.21 & 12.05 \\
\hline$M^{\prime *}$ (same sav non-per) & 0.01 & 0.01 & 3.35 & 5.04 & 91.60 & 76.54 & 50.89 & 12.89 \\
\hline$Q^{\prime *}$ (same sav per) & 0.00 & 0.00 & 4.28 & 6.39 & 89.32 & 77.23 & 52.43 & 12.59 \\
\hline
\end{tabular}

To sum up, we just want to point out that the conclusions under this more volatile earnings process strengthen those obtained with the less volatile Aiyagari's process. We find that precautionary savings (and aggregate capital) increase dramatically whereas our measures of inequality fall slightly, these effects being stronger for persistent habits. Also as before, we see that it is asset-poor households who proportionally raise more their asset holdings.

\section{Conclusion}

In this paper we have explored the role of habits in shaping the distribution of wealth. Our findings indicate that once we properly calibrate the economy to match the IES, the introduction of habits increases precautionary savings up to three times the (low) level of the benchmark model economy calibrated as in Aiyagari (1994). Its role in shaping inequality is that it reduces it: the inequality statistics go dow $\mathrm{n}$ in some cases $18 \%$. These differences $\mathrm{w}$ ith the benchmark economy are more pronounced when habits are persistent than when they are not. When we calibrate our economies using an earnings process that better matches the observed earnings inequality in the U.S. we find the same qualitative results. Precautionary savings increase substantially from an already very large value and inequality indicators decrease a bit, with changes being bigger for persistent habits economies.

Habits affect the way households dislike consumption fluctuations. In this class of incomplete markets economies, where households are subject to idiosyncratic shocks, income fluctuations are only partially insurable through the accumulation of assets. Households with a long stream of good shocks hold big amounts of assets and reach a satisfactory degree of insurance. Households with a long stream of bad shocks are left with few assets and therefore have to bear consumption fluctuations. Not surprisingly, the comparison between an economy with habit formation and an economy without habit formation shows that it is asset-poor people behavior that differs the most. Since the presence of habits makes consumption fluctuations more painful, those households with a small level of self-insurance will try to increase it by holding higher asset stocks. This makes the wealth distribution more even by reducing the number of people holding very low levels of assets. 


\section{Appendix A. Computational procedures}

To solve the consumer's problem described in Section 2.4 we follow a successive approximations approach in the value function. Our individual state space contains two endogenous individual variables (assets and habits) as well as the exogenous idiosyncratic shock. This implies the need to create a two-dimensional grid for the endogenous state and interpolate for solutions of assets and habits tomorrow different from the grid points. We will do this interpolation by two-dimensional splines. To our knowledge, there is no attempt done to solve a problem of this class through bidimensional splines. We explain below how we implement it. To solve for the steady state we proceed as follows. First, given a pair of prices $\{w, r\}$ we solve the household problem. Second, we compute the aggregate capital implied by this solution. This aggregate capital may or may not be consistent with the given prices $\{w, r\}$. If it is, they are the steady state prices. If it is not, we get a new pair $\left\{w^{\prime}, r^{\prime}\right\}$ and repeat the process. Below we describe the procedure in more detail

\section{A.1. Solving the household's problem}

The Contraction Mapping Theorem tells us that following a successive approximations strategy in the functional equation (1) will guarantee finding its fixed point. Moreover, any initial guess will do as long as it is concave in its endogenous arguments. More precisely, deriving the FOC we get the following system:

$$
\begin{aligned}
& 0=-u_{c}(c, h)+\beta \sum_{e^{\prime}} \pi_{e, e^{\prime}}\left[v_{a}\left(e^{\prime}, a^{\prime}, \psi(c, h)\right)-v_{h}\left(e^{\prime}, a^{\prime}, \psi(c, h)\right) \psi_{c}(c, h)\right], \\
& c=e w+(1+r) a-a^{\prime}
\end{aligned}
$$

which defines implicitly the policy functions $a^{\prime}=g^{a}(e, a, h)$ and $c=g^{c}(e, a, h)=$ $e w+(1+r) a-g^{a}(e, a, h)$. We substitute them back into Eq. (1) to get

$$
v(e, a, h)=u\left[g^{c}(e, a, h), h\right]+\beta \sum_{e^{\prime}} \pi_{e, e^{\prime}} v\left\{e^{\prime}, g^{a}(e, a, h), \psi\left[g^{c}(e, a, h), h\right]\right\} .
$$

First, we choose a family of functions that the computer can understand. The problem we face here is one of two endogenous choice state variables. This means that we will need to compute the value function at any point in a bidimensional continuous support as well as at each point of the Markov process. We choose a bispline interpolation over a grid on $a$ and $h$. Splines are very useful in this context because they guarantee continuous first and second derivatives. We need first derivatives to write the FOC and second derivatives to use Newton-based non-linear equation solvers. ${ }^{46}$ Then, we guess an initial value function $v^{0}$, solve numerically the

\footnotetext{
${ }^{46} \mathrm{We}$ construct the bispline approximation by use of a tensor product of two unidimensional splines. An explanation on howto compute tensor products over two spaces of interpolating functions can be found in De Boor (1978), chapter XVII. In particular we use the algorithm implemented in the IMSL subroutine DBSINT.
} 
FOC 7 and 8 at each point $\left(e_{i}, a_{j}, h_{k}\right)$ of the three-dimensional grid for the state space, get the policy functions $g^{0, a}\left(e_{i}, a_{j}, h_{k}\right)$ and $g^{0, c}\left(e_{i}, a_{j}, h_{k}\right)$, use the bispline interpolation to substitute them back into the functional equation (9) and get an updated $v^{1}$. If $v^{1}$ and $v^{0}$ are close enough we reached the fixed point. If they are not we iterate on, using $v^{1}$ instead of $v^{0}$ to get certain $v^{2}$.

There are two possible problems associated with the approach just described. The first one is that the Contraction Mapping Theorem does not necessarily hold once we restrict the space of continuous and bounded functions to which $v$ belongs to a some computer storable subspace. The second one is that the bispline approximation does not necessarily preserve concavity. Whereas we have not found any difficulty associated with the former problem, the latter deserves further comments. A spline is basically an interpolation mechanism that uses a third order polynomial in each interval between grid points. When a piece-wise linear approach is followed, what happens to a function to be approximated in one interval is totally independent of what happens to it in another one. However, this is not completely true for splines, since the requirement that first and second derivatives from the left and from the right at each grid point equal each other makes the polynomials in each interval not independent. A utility function is an object with sharp changes of slope, being first and second derivatives huge at low levels of $c$ and $h$ and much smaller at higher levels. This properties translate into the value function. Using few grid points means that, not only the approximation is worse than using many but also that certain properties of the function may be lost. Precisely, we observed that using a $15 \times 15$ grid $^{47}$ would lead, in the more extreme parameterizations, ${ }^{48}$ to a loss of concavity and, even worse, monotonicity. The reason of this is that the high first derivative of utility at low levels of $c$ is translated into the adjacent intervals so that the splines approximation overshoots the function to be approximated. Only slowly the slope of the spline can go down and recover, creating a hump. To solve this, one needs to use many grid points close to zero, the area where this happens, to make sure the spline slope can fall gradually. We increased the grid to $75 \times 20$ points. Notice that this means solving the household's problem for 4500 points at each iteration

\section{A.2. Solving for the steady state}

Here we follow a standard procedure. We choose an initial guess $r^{1}$ and solve the household problem to get $g_{r^{1}}^{a}(e, a, h)$ and $g_{r^{1}}^{c}(e, a, h)$. Then, we guess an initial sample of individuals of size 5000 and apply to them $g_{r^{1}}^{a}(e, a, h), g_{r^{1}}^{c}(e, a, h)$ and the law of motion for the Markov process 3000 times, which ensures in all experiments we have done that the main statistics of the sample are almost constant. This gives us the

\footnotetext{
${ }^{47}$ More dense close to the zeros than close to the upper bounds.

${ }^{48}$ More extreme parameterizations mean high $\sigma$, high $\gamma$ and high variability of the earnings process. All these three characteristics create higher differences in the marginal utility of consumption across grid points. The problems would first arise at those points with low consumption and high habits because the lower the consumption and the higher the habit, the higher the marginal utility of consumption.
} 
aggregate assets in the economy $A_{r^{1}}$. Then, we find $r^{2}$ such that the demand of capital by firms, $K(r)$ equals $A_{r^{1}}$. Say $r^{1}<r^{2}$ (if not, relabel). Since capital demand is decreasing in $r$ and aggregate assets are increasing in $r$, the steady state interest rate $r^{*}$ belongs to the interval $\left(r^{1}, r^{2}\right)$. From this point we start the iterative procedure. We take the middle point in the interval, call it $r^{3}$, and get the associated $A_{r^{3}}$. If $A_{r^{3}}<K\left(r^{3}\right)$ the interest rate we have tried is too small, so we set $r^{1}=r^{3}$ and start again. If $A_{r^{3}}>K\left(r^{3}\right)$ the interest rate we have tried is too big, so we set $r^{2}=r^{3}$ and start again. We stop when the distance between $r^{1}$ and $r^{2}$ is arbitrarily small. To ensure no sampling error is spoiling the convergence to $r^{*}$ we use the same seed to initialize the random number generator in each iteration.

Some of our model economies (case of $M$ and $Q$ ) are set to have the same interest rate and aggregate capital as a given one $(B)$ by adjusting the time preference parameter $\beta$. The procedure used to get the steady state in these cases differs from the one just described in that $r$ is fixed and in that we have to iterate in different values of $\beta$. The initialization of the procedure is not so clean because it is not possible to compute an interval $\left(\beta^{1}, \beta^{2}\right)$ where our $\beta^{*}$ belongs to. We proceed as follows. We guess an initial $\beta^{1}$. If $A_{\beta^{1}}<K^{*}$ we know we have a lower bound. If $A_{\beta^{1}}>K^{*}$ we know we have an upper bound. In the former (respectively latter) case we try higher (lower) betas until we find a $\beta^{2}$ for which $A_{\beta^{2}}>K^{*}\left(A_{\beta^{2}}<K^{*}\right)$. Then, since capital demand is invariant in beta and aggregate assets are increasing, we know that $\beta^{*} \in\left(\beta^{1}, \beta^{2}\right)$. From this point we can apply to $\beta$ instead to $r$ the iterative procedure described in the previous paragraph.

\section{Appendix B. IES}

To correctly compare the habits economies with the non-habits economy we want to make them equal in certain dimensions. One of these dimensions is the IES. The follow ing result gives the explicit form for the IES in the economies with proportional habits (Carroll et al. (2000)). In general the IES is not constant for different consumption and habit values. How ever, it can be nicely characterized along a balanced grow th consumption path. Notice in addition that the IES is independent of the persistence of the habit stock.

Lemma B.1. For the certainty case with multiplicative habit, the IES in the steady state is independent of $\lambda$ and equal to $1 /(\gamma+(1-\gamma) \sigma)$.

Proof. Recall that the instantaneous utility function is $u(c, h)=\left(\left(c h^{-\gamma}\right)^{1-\sigma}-1\right) /$ $(1-\sigma)$, with $1>\gamma>0$. The Euler equation is

$$
\begin{aligned}
& c_{t}^{-\sigma} h_{t}^{\gamma(\sigma-1)}-\beta \gamma \lambda \sum_{i=1}^{\infty}[\beta(1-\lambda)]^{i-1} x_{t+i} \\
& \quad=\beta(1+r)\left\{c_{t+1}^{-\sigma} h_{t+1}^{\gamma(\sigma-1)}-\beta \gamma \lambda \sum_{i=1}^{\infty}[\beta(1-\lambda)]^{i-1} x_{t+1+i}\right\},
\end{aligned}
$$


where $x_{t}=c_{t}^{1-\sigma} h_{t}^{\gamma(\sigma-1)-1}$. Then, we can write the stock of habit as a function of all past consumption:

$$
h_{t+1}=(1-\lambda) h_{t}+\lambda c_{t}=\lambda \sum_{i=0}^{\infty}(1-\lambda)^{i} c_{t-i} .
$$

A balanced growth path requires that $c_{t}=\eta^{t} c^{*}$ which implies that the habit stock is $h_{t}=A \eta^{t} c^{*}$, with $A=\lambda /(\eta-(1-\lambda))$, which means that consumption and habit stock grow at the same rate. Also along a balanced growth path, $x_{t}=$ $A^{\gamma(\sigma-1)-1} c_{t}^{-[\gamma+(1-\gamma) \sigma]}$.

Substituting in the Euler equation $h_{t}$ and $x_{t}$ by their balanced growth path values we obtain:

$$
\begin{aligned}
& A c^{-[\gamma+(1-\gamma) \sigma]}-\beta \gamma \lambda B \eta^{-[\gamma+(1-\gamma) \sigma]} c^{-[\gamma+(1-\gamma) \sigma]} \\
& \quad=\beta(1+r)\left\{A \eta^{-[\gamma+(1-\gamma) \sigma]} c^{-[\gamma+(1-\gamma) \sigma]}-\beta \gamma \lambda B \eta^{-2[\gamma+(1-\gamma) \sigma]} c^{-[\gamma+(1-\gamma) \sigma]}\right\},
\end{aligned}
$$

where

$$
B \equiv \sum_{i=0}^{\infty}[\beta(1-\lambda)]^{i}\left[\eta^{-[\gamma+(1-\gamma) \sigma]}\right]^{i}=\frac{1}{1-\beta(1-\lambda) \eta^{-[\gamma+(1-\gamma) \sigma]}}
$$

Using $\eta^{-[\gamma+(1-\gamma) \sigma]}$ as common factor in the right hand side dramatically simplifies this expression until we get $1=\beta(1+r) \eta^{-[\gamma+(1-\gamma) \sigma]}$ from where the IES can be directly evaluated yielding the value of $1 /(\gamma+(1-\gamma) \sigma)$.

Under certain conditions, for habit preferences with survival consumption, the IES also has a simple expression.

Lemma B.2. The IES of habit preferences with survival consumption along a balanced growth consumption path is independent of $\gamma$, and $\lambda$ and is equal to $1 / \sigma$.

Proof. Recall that the instantaneous utility function is $u(c, h)=\left((c-\gamma h)^{1-\sigma}-\right.$ $1) /(1-\sigma)$, with $1>\gamma>0$. Its Euler equation is

$$
\begin{aligned}
& \left(c_{t}-\gamma h_{t}\right)^{-\sigma}-\beta \gamma \lambda \sum_{i=1}^{\infty}[\beta(1-\lambda)]^{i-1}\left(c_{t+i}-\gamma h_{t+i}\right)^{-\sigma} \\
& \quad=\beta(1+r)\left\{\left(c_{t+1}-\gamma h_{t+1}\right)^{-\sigma}-\beta \gamma \lambda \sum_{i=1}^{\infty}[\beta(1-\lambda)]^{i-1}\left(c_{t+1+i}-\gamma h_{t+1+i}\right)^{-\sigma}\right\} .
\end{aligned}
$$

Again, the stock of habit is given by $h_{t+1}=(1-\lambda) h_{t}+\lambda c_{t}=\lambda \sum_{i=0}^{\infty}(1-\lambda)^{i} c_{t-i}$. Along a balanced growth path we have $c_{t}=\eta^{t} c^{*}$. which implies that the habit stock is $h_{t}=A \eta^{t} c^{*}$, with $A=\lambda /(\eta-(1-\lambda))$, which means that consumption and habit 
stock grow at the same rate. Replacing the stock of habits in the Euler equation along a balanced growth path yields

$$
\begin{aligned}
& c^{-\sigma}(1-\gamma A)^{-\sigma}-\beta \gamma \lambda(1-\gamma A)^{-\sigma} B \eta^{-\sigma} c^{-\sigma} \\
& \quad=\beta(1+r)\left\{\eta^{-\sigma} c^{-\sigma}(1-\gamma A)^{-\sigma}-\beta \gamma \lambda(1-\gamma A)^{-\sigma} B \eta^{-2 \sigma} c^{-\sigma}\right\},
\end{aligned}
$$

where

$$
B \equiv \sum_{i=0}^{\infty}\left[\beta(1-\lambda) \eta^{-\sigma}\right]^{i}=\frac{1}{1-\beta(1-\lambda) \eta^{-\sigma}} .
$$

Using $\eta^{-\sigma}$ as common factor in the right hand side dramatically simplifies this expression until we get $1=\beta(1+r) \eta^{-\sigma}$ from where the IES can be directly evaluated yielding the value of $1 / \sigma$.

\section{Appendix C. Risk aversion}

We proceed as Ferson and Constantinides (1991). Consider the following problem,

$$
\begin{aligned}
v\left(a_{t}, h_{t}\right)=\operatorname{Max} & \sum_{i=0}^{\infty} \beta^{i-1} \frac{\left(c_{t+i} h_{t+i}^{-\gamma}\right)^{1-\sigma}}{1-\sigma} \\
\text { s.t. } & \sum_{i=0}^{\infty}\left(\frac{1}{1+r}\right)^{i} c_{t+i}=a_{t}, \\
& h_{t+i}=(1-\lambda) h_{t+i-1}+\lambda c_{t+i-1} .
\end{aligned}
$$

The solution for this problem is a policy function $c_{t+i}\left(a_{t}, h_{t}\right)$, that specifies consumption at each period $t+i$. We define

$$
U_{t}=\sum_{i=0}^{\infty} \beta^{i-1} \frac{\left(c_{t+i} h_{t+i}^{-\gamma}\right)^{1-\sigma}}{1-\sigma},
$$

that is, utility for a given stream of consumption starting at period $t$. Notice that $U_{t}=u\left(c_{t}, h_{t}\right)+\beta U_{t+1}$, where $u\left(c_{t}, h_{t}\right)$ denotes instantaneous utility.

We follow Boldrin et al. (1997) and define an enhanced measure of risk aversion in consumption as

$$
R R A_{c}=-\frac{\frac{\partial^{2} u\left(c_{t}, h_{t}\right)}{\partial c_{t}^{2}}+\beta \frac{\partial^{2} v\left(a_{t+1}, h_{t+1}\right)}{\partial h_{t+1}^{2}}\left(\frac{\partial h_{t+1}}{\partial c_{t}}\right)^{2}}{\frac{\partial u\left(c_{t}, h_{t}\right)}{\partial c_{t}}+\beta \frac{\partial v\left(a_{t+1}, h_{t+1}\right) \partial h_{t+1}}{\partial c_{t+1}} c_{t}} .
$$

This measure adds to the Arrow-Pratt measure of risk aversion (which is just the first term) another term that tracks the effect that is propagated towards the future. In words, this measure takes into account that a change in current consumption, 
holding constant the value of next period wealth induces a change in the optimal path of consumption due to the change in habits. Let us call $c_{t+i}\left(a_{t+1}, h_{t+1}\right)$ the level of consumption from period $t+1$ onwards associated to the initial wealth $a_{t+1}$ and stock of habits $h_{t+1}$. Then, define $\mathrm{d} v\left(a_{t}, h_{t}\right) / \mathrm{d} c_{t}$, the derivative of the value function assuming that $a_{t+1}$ does not change with $c_{t}$,

$$
\begin{aligned}
\frac{\mathrm{d} v\left(a_{t}, h_{t}\right)}{\mathrm{d} c_{t}} & =\frac{\partial U_{t}}{\partial c_{t}}+\sum_{i=1}^{\infty} \beta^{i} \frac{\partial U_{t+i}}{\partial c_{t+i}} \frac{\partial c_{t+i}}{\partial h_{t+1}} \lambda \\
& =\frac{\partial U_{t}}{\partial c_{t}}\left[1+\frac{\partial U_{t+1} / \partial c_{t+1}}{\partial U_{t} / \partial c_{t}} \beta \sum_{i=1}^{\infty} \beta^{i-1} \frac{\partial U_{t+i} / \partial c_{t+i}}{\partial U_{t+1} / \partial c_{t+1}} \frac{\mathrm{d} c_{t+i}}{\mathrm{~d} h_{t+1}} \lambda\right] .
\end{aligned}
$$

The Euler equation tells us that $\partial U_{t} / \partial c_{t}=\beta(1+r) \partial U_{t+1} / \partial c_{t+1}$, therefore,

$$
\frac{\mathrm{d} v\left(a_{t}, h_{t}\right)}{\mathrm{d} c_{t}}=\frac{\partial U_{t}}{\partial c_{t}}\left[1+\frac{1}{1+r} \sum_{i=1}^{\infty}\left(\frac{1}{1+r}\right)^{i-1} \frac{\mathrm{d} c_{t+i}}{\mathrm{~d} h_{t+1}} \lambda\right] .
$$

Differentiating the intertemporal budget constraint that starts at $t+1$, we obtain that

$$
\sum_{i=1}^{\infty}\left(\frac{1}{1+r}\right)^{i-1} \frac{\mathrm{d} c_{t+i}}{\mathrm{~d} h_{t+1}} \lambda=0 .
$$

And therefore, $\mathrm{d} v\left(a_{t}, h_{t}\right) / \mathrm{d} c_{t}=\partial U_{t} / \partial c_{t}$. Thus,

$$
\begin{aligned}
R R A_{c} & =-\frac{\partial^{2} U_{t} / \partial c_{t}^{2}}{\partial U_{t} / \partial c_{t}} c_{t}-\sum_{i=1}^{\infty} \frac{\partial^{2} U_{t} / \partial c_{t+i} \partial c_{t}}{\partial U_{t} / \partial c_{t}} \frac{\mathrm{d} c_{t+i}}{\mathrm{~d} h_{t+1}} \lambda c_{t} \\
& =-\frac{\partial^{2} U_{t} / \partial c_{t}^{2}}{\partial U_{t} / \partial c_{t}} c_{t}-\sum_{i=1}^{\infty} \frac{\partial^{2} U_{t} / \partial c_{t+i} \partial c_{t}}{\partial U_{t} / \partial c_{t}} \frac{\mathrm{d} c_{t+i}}{\mathrm{~d} h_{t+1}}\left(h_{t+1}-h_{t}+\lambda h_{t}\right) .
\end{aligned}
$$

In a stationary allocation, $h_{t+1}-h_{t}=0$ and $\mathrm{d} c_{t+i} / \mathrm{d} h_{t+1} \lambda h_{t} \approx \lambda\left(\mathrm{d} c_{t+i} / \mathrm{d} h_{t+1}\right) h_{t+1}$. This is a first order approximation to the true policy function, $\left(\mathrm{d} c_{t+i} / \mathrm{d} h_{t+1}\right) h_{t+1} \approx c_{t+i}$,

$$
R R A_{c} \approx-\frac{\partial^{2} U_{t} / \partial c_{t}^{2}}{\partial U_{t} / \partial c_{t}} c_{t}-\lambda \sum_{i=1}^{\infty} \frac{\partial^{2} U_{t} / \partial c_{t+i} \partial c_{t}}{\partial U_{t} / \partial c_{t}} c_{t+i}
$$

Hence in a stationary allocation,

$$
\begin{aligned}
R R A_{c} \approx & \frac{\sigma-[\gamma(1-\sigma)+1]_{\left[1-\beta(1-\lambda)^{2}\right]}}{1-\frac{\gamma \lambda^{2}}{1-\beta(1-\lambda)}} \\
& +\lambda \frac{\frac{\gamma \lambda \beta}{1-\beta(1-\lambda)}}{1-\frac{\gamma \lambda \beta}{1-\beta(1-\lambda)}}\left[(1-\sigma)-\frac{\lambda(1-\lambda) \beta[\gamma(1-\sigma)+1]]}{\left[1-\beta(1-\lambda)^{2}\right]}\right] .
\end{aligned}
$$

For the chosen calibration, the enhanced measure of risk aversion in consumption is larger in the persistent habits economies than in the non-persistent counterparts. In both cases, risk aversion is larger than in the non-habits economies. 


\section{References}

Abel, A., 1990. Assets prices under habit formation and catching up with the joneses. American Economic Review 89 (2), 38-42.

Abowd, J.M., Card, D., 1987. Intertemporal labor supply and long term employment contracts. American Economic Review 77, 50-68.

Abowd, J.M., Card, D., 1989. On the covariance structure of earnings and hours changes. Econometrica 57 (2), 411-445.

Aiyagari, S.R., 1994. Uninsured idiosyncratic risk, and aggregate saving. Quarterly Journal of Economics $109,659-684$.

Alvarez, M.J., Díaz, A., 2000. Minimum consumption, transitional dynamics and the kuznets curve. Mimeo, Universidad Carlos III de Madrid.

Boldrin, M., Christiano, L., Fisher, J., 1997. Habit persistence and asset returns in an exchange economy. Macroeconomic Dynamics 1 (2), 312-332.

Boldrin, M., Christiano, L., Fisher, J., 2001. Habit persistence and asset returns and the business cycle. American Economic Review 91 (1), 149-166.

Browning, M., Lusardi, A., 1996. Household saving: micro theories and micro facts. Journal of Economic Literature 34, 1797-1855.

Cagetti, M., 2000. Wealth accumulation over the life cycle and precautionary savings. Mimeo, University of Virginia.

Campbell, J., Cochrane, J., 1999. By force of habit: a consumption-based explanation of aggregate shock market behavior. Journal of Political Economy 107 (2), 205-251.

Carroll, C.D., 2000. Why do the rich save so much? In: Slemrod, J.B. (Ed.), Does Atlas Shrug? The Economic Consequences of Taxing the Rich. Harvard University Press, Cambridge, MA.

Carroll, C.D., Samwick, A.A., 1997. The nature of precautionary wealth. Journal of Monetary Economics 40, 41-71.

Carroll, C.D., Samwick, A.A., 1998. How important is precautionary saving? Review of Economics and Statistics 80 (3), 410-419.

Carroll, C., Weil, D., 1994. Saving and growth: a reinterpretation. Carnegie-Rochester Conference Series on Public Policy 40, 133-192.

Carroll, C., Overland, J., Weil, D., 2000. Saving and growth with habit formation. American Economic Review 90 (3), 341-355.

Castañeda, A., Díaz-Giménez, J., Ríos-Rull, J.V., 2001. Accounting for earnings and wealth inequality. Mimeo, University of Pennsylvania.

Chatterjee, S., 1994. Transitional dynamics and the distribution of wealth in a neoclassical growth model. Journal of Public Economics 54 (1), 97-119.

Constantinides, G., 1990. Habit formation: a resolution of the equity premium puzzle. Journal of Political Economy 98 (3), 519-543.

Cooley, T.F., Prescott, E.C., 1995. Economic growth and business cycles. In: Cooley, T.F. (Ed.), Frontiers of Business Cycle Research, Princeton University Press, Princeton (Chapter 1).

De Boor, C., 1978. A Practical Guide to Splines. Springer, New York.

Deaton, A., Paxson, C., 1994. Saving, growth, and aging in Taiwan. In: Wise, D.A. (Ed.), Studies in the Economics of Ageing. University of Chicago Press, Chicago Studies in the economics of aging. National Bureau of Economic Research Project Report Series, pp. 331-357.

Díaz-Gimenez, J., Quadrini, V., Ríos-Rull, J.-V., 1997. Dimensions of inequality: facts on the U.S. distribution of earnings, income and wealth. Federal Reserve Bank of Minneapolis Quarterly Review 21, 3-21.

Dynan, K.E., 1993. How prudent are consumers? Journal of Political Economy 101 (6), 1104-1113.

Dynan, K.E., 2000. Habit formation in consumer preferences: evidence form panel data. American Economic Review 90 (3), 391-406.

Edwards, S., 1995. Why are savings rates so different across countries?: an international comparative analysis. NBER Working Paper 5097. 
Ferson, W.E., Constantinides, G., 1991. Habit persistence and durability in aggregate consumption. Journal of Financial Economics 29 (2), 199-240.

Fuhrer, J.C., 2000. Habit formation in consumption and its implications for monetary policy models. American Economic Review 90 (3), 367-390.

Ghez, G., Becker, G.S., 1975. The Allocation of Time and Goods Over the Life Cycle. Columbia University Press, New York.

Heaton, J., 1995. An empirical investigation of asset pricing with temporally dependent preference specification. Econometrica 63 (3), 681-717.

Hopenhayn, H., Prescott, E.C., 1992. Stochastic monotonicity and stationary distributions for dynamic economies. Econometrica 60, 1387-1406.

Hubbard, G., Skinner, J., Zeldes, S., 1994. The importance of precautionary motives in explaining individual and aggregate saving. Carnegie-Rochester Conference Series on Public Policy 40, 59-125.

Huggett, M., 1993. The risk free rate in heterogeneous-agents, incomplete insurance economies. Journal of Economic Dynamics and Control 17 (5/6), 953-970.

Huggett, M., 1996. Wealth distribution in life-cycle economies. Journal of Monetary Economics 38 (3), 469-494.

Hurd, M.D., 1989. Mortality risk and bequests. Econometrica 57 (4), 779-813.

Krusell, P., Smith, A., 1997. Income and wealth heterogeneity, portfolio choice, and equilibrium asset returns. Macroeconomic Dynamics 1 (2), 387-422.

Krusell, P., Smith, A., 1998. Income and wealth heterogeneity in the macroeconomy. Journal of Political Economy 106, 867-896.

Kydland, F.E., 1984. Labor-force heterogeneity and the business cycle. Carnegie-Rochester Conference Series on Public Policy 21, 173-209.

Kydland, F.E., Prescott, E.C., 1982. Time to build and aggregate fluctuations. Econometrica 50 (6), 1345-1370.

MaCurdy, T.E., 1981. An empirical model of labor supply in a life-cycle setting. Journal of Political Economy 89, 1059-1085.

Meghir, C., Weber, G., 1996. Intertemporal nonseparability or borrowing restrictions? a disaggregate analysis using a U.S. consumption panel. Econometrica 64 (5), 1151-1181.

Mehra, R., Prescott, E., 1985. The equity premium: a puzzle. Journal of Monetary Economics 15, $145-161$.

Pijoan-Mas, J., 2003. Pricing risk in economies with heterogeneous agents and incomplete markets. CEMFI working paper 0305.

Prescott, E.C., 1986. Theory ahead of business cycle measurement. Carnegie-Rochester Conference Series on Public Policy 25 (0), 11-44 Also in Federal Reserve Bank of Minneapolis Quarterly Review 10 (4) $9-22$.

Quadrini, V., Ríos-Rull, J.-V., 1997. Understanding the U.S. distribution of wealth. Federal Reserve Bank of Minneapolis Quarterly Review 21, 22-36.

Ríos-Rull, J.-V., 1998. Computing equilibria in models with heterogenous agents. In: Marimon, R., Scott, A. (Eds.), Computational Methods for the Study of Dynamic Economics, Oxford University Press, Oxford, pp. 238-264 (Chapter 9).

Ryder Jr., H.E., Heal, G.M., 1973. Optimal growth with intertemporally dependent preferences. Review of Economic Studies 40 (1), 1-31.

Tauchen, G., 1986. Finite state Markov-chain approximations to univariate and vector autoregressions. Economics Letters 20, 177-181. 